\title{
Biodiversity and Multifunctional Features of Lactic Acid Bacteria Isolated From Table Olive Biofilms
}

\section{Antonio Benítez-Cabello, Beatriz Calero-Delgado, Francisco Rodríguez-Gómez, Antonio Garrido-Fernández, Rufino Jiménez-Díaz and Francisco Noé Arroyo-López*}

Department of Food Biotechnology, Instituto de la Grasa, Agencia Estatal Consejo Superior de Investigaciones Científicas Pablo de Olavide University, Seville, Spain

In the present study, a total of 554 lactic acid bacteria (LAB) isolates were obtained from the olive surface of Manzanilla, Gordal, and Aloreña cultivars processed as green Spanish-style or directly brined (natural) olives. The isolates obtained from industrial processes were genotyped by rep-PCR with primer $\mathrm{GTG}_{5}$, collecting a total of 79 different genotypes. The $\alpha$-biodiversity indexes showed that the LAB diversity was higher in the biofilms on the fruits which followed the Spanish-style process than in those just brined. Sixteen genotypes had a frequency higher $>1 \%$ and were identified, by multiplex PCR recA gene and $16 \mathrm{~S}$ gene sequencing, as belonging to Lactobacillus pentosus $(n=13)$ and Lactobacillus plantarum $(n=3)$ species. A multivariate analysis based on a dataset with 89,744 cells, including technological (resistance to salt and $\mathrm{pH}$, production of lactic acid, auto and co-aggregation with yeast species, $\beta$-glucosidase and esterase activities), and potential probiotic characteristics (survival to gastric and pancreatic digestions, resistance to antibiotics, inhibition of pathogens, presence of bsh genes, cholesterol removal, hemolytic, $\alpha$-glucosidase, $\beta$-galactosidase, and phytase activities) showed that the 16 genotypes could be grouped into 3 great phenotypes. Thus, the genotype biodiversity in table olive biofilms was limited but, at phenotype level, it was even lower since L. pentosus predominated clearly (80.15\% isolates). L. pentosus Lp13 was the genotype with the most promising characteristics for its use as a multifunctional starter, with this strain being and ubiquitous microorganism present in both natural and lye-treated olive fermentations.

Keywords: Spanish-style green olives, natural olives, genotyping, multifunctional starters, biofilms

\section{INTRODUCTION}

Table olives are a traditional fermented vegetable with many centuries of history in the Mediterranean basin, where this food has a great influence on the diet and culture of many countries. The world production of table olives exceeded $2.9 \times 10^{6}$ tones in 2017/2018 season, with more than $80 \%$ of the total output being processed by the Mediterranean leading countries Spain, Egypt, Turkey, Algeria, Italy, Greece, and Portugal (IOC, 2019). However, South America, Australia, and the Middle East are also emerging as promising producers.

The olive fruit is a fleshy drupe. It has a bitter compound (oleuropein), so olives cannot be consumed directly from the tree and need to be processed to make them palatable. Thereby, the 
most recognized table olive industrial processing methods are, in order of importance: (i) Spanish-style (alkali treated green olives), (ii) Californian-style (ripe olives by alkaline oxidation), and (iii) natural or directly brined olives (green, turning color or naturally black olives) (Garrido-Fernández et al., 1997).

The processing and preservation of table olives by fermentation is carried out by a combination of sugar consumption, natural acidification and salting influenced by microorganisms, which determine the flavor, safety, and quality of the final products (Arroyo-López et al., 2015). Regardless of the process, lactic acid bacteria (LAB) species play an essential role by transforming the sugars present in olive flesh into lactic which leads to rapid acidification of brines. Also, the eventual release of bacteriocins may help (Hurtado et al., 2012). Lactobacillus plantarum and Lactobacillus pentosus are the predominant species in most olive fermentations but, depending on the olive cultivar, the processing method and the geographical origin, other lactobacilli or genera can predominate or even be the most abundant species (Hurtado et al., 2012; Heperkan, 2013).

In many industries, table olive fermentations still occur spontaneously. Thus, the process is not entirely predictable and can lead to alteration and food waste (Lanza, 2013). This way, the selection of autochthonous LAB with technological and/or potential probiotic characteristics has been carried out during the last years with the objective of developing starters with application in table olives. Many of these selected microorganisms have been validated at pilot and industrial scale with promising results such us high frequencies of imposition, acidification rates, production of aromas, formation of biofilms, etc. (De Bellis et al., 2010; Ruiz-Barba and Jiménez-Díaz, 2012; Blana et al., 2014; Martorana et al., 2017; Rodríguez-Gómez et al., 2017; Chranioti et al., 2018; Pino et al., 2018). In most of the cases, the isolation of LAB was carried out exclusively from brines (Argyri et al., 2013; Bautista-Gallego et al., 2013; Botta et al., 2014; Peres et al., 2014), whilst the presence of LAB species forming biofilms on olive epidermis has been proved recently (ArroyoLópez et al., 2012; Domínguez-Manzano et al., 2012; BenítezCabello et al., 2015). Only microorganisms with the ability to adhere to fruits epidermis could be transported to consumers during consumption, turning olives into a probiotic food if they have demonstrated functional characteristics. Besides, the application of molecular methods has shown that the biodiversity of LAB in olive brines is sensibly higher (Abriouel et al., 2011, 2012; Lucena-Padrós et al., 2014a,b; Tofalo et al., 2014; Comunian et al., 2017) than previously estimated. However, scarce studies have been carried out to determine LAB biodiversity exclusively in olive biofilms and testing their biotechnological potential (Arroyo-López et al., 2012; Domínguez-Manzano et al., 2012; Benítez-Cabello et al., 2015).

This study aimed to search, among LAB biodiversity present exclusively in olive biofilms, for isolates with multifunctional properties of interest for the fabrication of starter cultures for table olives. For this purpose, a multidisciplinary approach using molecular, biochemical, and statistical techniques was used for the selection of suitable strains, which comprises the detachment and isolation of LAB from fruit epidermis, genotyping, clustering, identification, study of their technological and probiotic features, and finally, selection of the most promising strains by multivariate analysis.

\section{MATERIALS AND METHODS}

\section{Olive Samples}

The fruit used in the study were taken along the fermentation process (3-90 days) from 14 fermentation vessels (6 for Gordal and 8 for Manzanilla) processed as green Spanish-style, and from 10 fermentation vessels ( 2 for Manzanilla, 2 for Gordal, and 6 for Aloreña) of directly brined (natural) olives. The visited industries (6) were from the Sevilla and Málaga provinces (Spain) and the sampling period included three consecutive seasons (2014-2017). A total of 554 isolates (245 from Gordal, 259 from Manzanilla, and 50 from Aloreña cultivars) were obtained for molecular analysis.

\section{Detachment and Isolation of LAB From Olive Biofilms}

Biofilms-forming LAB isolates were recovered from olive surface according to the methodology described by Benítez-Cabello et al. (2015). Briefly, fruits were removed under sterile conditions from the fermentation vessels, transported to the laboratory and transferred into sterile distilled water for $30 \mathrm{~min}$ for removing non-adhered cells to olive surface. Then, fruits were pitted and $25 \mathrm{~g}$ immediately transferred into a stomacher bag containing $75 \mathrm{ml}$ of a sterile saline solution $(0.9 \% \mathrm{NaCl})$. Pulp was homogenized for $2 \mathrm{~min}$ at maximum speed $(300 \mathrm{rpm}$ ) in a stomacher model Seward 400 (Seward Medical Ltd., West Sussex, United Kingdom). Suspension of the appropriate dilutions were then spread in Man, Rogosa and Sharpe (MRS) agar selective medium (Oxoid, Basingstoke, Hampshire, United Kingdom) supplemented with $0.02 \%$ sodium azide (Sigma, St. Louis, MO, United States). After $48 \mathrm{~h}$ incubation at $37^{\circ} \mathrm{C}$, colonies were isolated, grown again in MRS broth at $37^{\circ} \mathrm{C}$ for $48 \mathrm{~h}$ and stored at $-80^{\circ} \mathrm{C}$ in $20 \%$ glycerol (v/v) until further analysis.

\section{Molecular Genotyping and Identification of LAB Isolates}

DNA of the $554 \mathrm{LAB}$ isolates was extracted from $1 \mathrm{~mL}$ of early culture in MRS broth $\left(\mathrm{OD}_{600 \mathrm{~nm}}=1.0\right)$ with the rapid chloroform:isoamyl alcohol method described by Ruiz-Barba et al. (2005), and further amplified by rep-PCR analysis using the $\mathrm{GTG}_{5}$ primer and protocol described by Gevers et al. (2001). PCR products were electrophoresed in a $2 \%$ agarose gel and finally stained with ethidium bromide $(20 \mathrm{~min})$. The gel was visualized under ultraviolet light using a gel analyser model Enduro ${ }^{\mathrm{TM}}$ GDS (Labnet International, Inc., United States).

The resulting fingerprints were digitally captured and analyzed with the BioNumerics 6.6 software package (Applied Maths, Kortrijk, Belgium). Only bands representing amplicons between 100 and 3,000 bp in size were included in the analysis. The similarity among digitalised profiles was calculated using the Pearson correlation coefficient, and the dendrogram was generated using the Unweighted Pair Group Method using the 
Arithmetic Average clustering algorithm, setting a value of $0.5 \%$ optimisation and $1.25 \%$ curve smoothing. Similarity coefficient $85.0 \%$ was considered as a cut-off value to discriminate between genotypes. This cut-off value was selected by using $L$. pentosus TOMC $L A B 2$, which was included in all PCR reactions as an internal control. A representative isolate from each cluster was automatically selected by a script of the BioNumerics software whose algorithm determines the fingerprint profile that share a greater similarity with the maximum number of isolates present in the cluster.

Molecular identification of predominant genotypes ( $>1 \%$ isolation frequency) was performed by sequencing the $16 \mathrm{~S}$ rDNA gene using the oligonucleotide pairs 27F/1492R (Barrangou et al., 2002). The percentage of identity of the sequences was determined through a Blast analysis with the available sequences from the NCBI GenBank database ${ }^{1}$. Since $16 \mathrm{~S}$ rDNA sequence analysis could not differentiate at species level within L. plantarum group, a multiplex PCR of the recA gene was carried out to discriminate between L. pentosus, L. plantarum, and L. paraplantarum species (Torriani et al., 2001).

\section{Estimation of the Biodiversity Indexes}

Simpson's index of diversity represents the probability that two individuals randomly selected from a sample will belong to different species. The value of this index ranges between 0 and 1 , with values increasing as greater is the sample diversity; it is based on the formula: $1-\left[\Sigma(n / N)^{2}\right]$, where " $n$ " is the total number of organisms of a particular species, and " $N$ " the total number of organisms of all species. The Shannon-Wiener Index is defined as $H^{\prime}=-\Sigma[(p i) \times \ln (p i)]$, where $p i$ is the proportion of individuals found in species $i$. The proportion ( $p i)$ is estimated as $p i=n i / N$, where $n i$ is the number of individuals in species $i$ and $N$ is the total number of individuals in the community. Typical values are generally between 1.5 and 3.5, with increasing values indicating greater sample diversity (Magurran, 2004). Shannon $\left(H^{\prime}\right)$ and Simpson's $(1-D)$ indexes of $\alpha$-diversity were calculated at the genotype level using the Scripts available in the BioNumerics 6.6 software package.

\section{Assessment of the Technological Potential}

All technological assays described below were executed in triplicate. To study the effect of $\mathrm{NaCl}$ on the predominant LAB genotypes, the MRS broth was supplemented with $\mathrm{NaCl}$ to obtain the following final concentrations of salt in the media: 0, 5, 10, 20, 30, 40, 60, 80, 100, 120, and $160 \mathrm{~g} / \mathrm{L}$. Then, LAB growth was monitored in a Bioscreen $\mathrm{C}$ automated spectrophotometer (Labsystems, Helsinki, Finland) for 7 days at $30^{\circ} \mathrm{C}$ with a wideband filter $(420-580 \mathrm{~nm})$. A total of 528 growth curves were modeled for the estimation of the NIC and MIC parameters using the reparametrized Gompertz function for decay (Bonatsou et al., 2015).

To study the effect of $\mathrm{pH}$ on the predominant LAB genotypes, the MRS broth was modified with $\mathrm{HCl}(0.5 \mathrm{~N})$ to obtain the following $\mathrm{pH}$ in the medium $(2,3,4,5,6,7,8,9$,

\footnotetext{
${ }^{1}$ http://blast.ncbi.nlm.nih.gov/Blast.cgi
}

10,11 , and 12). Then, as in the previous case, LAB growth was monitored in a Bioscreen $\mathrm{C}$ automated spectrophotometer (Labsystems, Helsinki, Finland) for 7 days at $30^{\circ} \mathrm{C}$ with a wideband filter (420-580 nm). A total of 528 growth curves were modeled for the estimation of $\mathrm{pH}$ cardinal parameters $\left(\mathrm{pH}_{\mathrm{opt}}\right.$, $\mathrm{pH}_{\max }$, and $\left.\mathrm{pH}_{\min }\right)$ using the cardinal model with inflection proposed by Oscar (2002).

To evaluate the production of lactic acid by the predominant $\mathrm{LAB}$ genotypes, isolates were grown in $25 \mathrm{~mL}$ of MRS broth supplemented with $6 \% \mathrm{NaCl}$ (a similar concentration obtained in olive brines). After $48 \mathrm{~h}$ incubation at $37^{\circ} \mathrm{C}$, suitable dilutions were made and plated on MRS agar to check the population level, reaching all strains similar final concentrations $\left(\sim 8 \log _{10}\right.$ $\mathrm{CFU} / \mathrm{mL}$ ). The percentage of titratable acidity was measured by using a Titroprocessor model 670 (Metrohm, Switzerland). The titratable acidity was expressed in g of lactic acid/100 mL.

Co-aggregation ability of the LAB genotypes with yeasts (Debaromyces etchellsii Y24 and Candida boidinii Y5) was studied following the protocol proposed by Toledo-Arana et al. (2001), which include co-incubation of the LAB and yeasts cultures, washing, staining with crystal violet and solubilization with ethanol-acetone. The $\mathrm{OD}_{595}$ was determined using a spectrophotometer SPECTROstar ${ }^{\circledR}$ Nano (BMG Labtech). These strains were chosen because of their weak (Y24) and high (Y5) ability to form biofilms with table olive Lactobacillus strains (León-Romero et al., 2006).

The ability to produce enzymes of technological interest (esterase and $\beta$-glucosidase activities) by the LAB strains was also studied. These activities were evaluated by measuring the amount of $p$-nitrophenol liberated from different chromogenic substrates (4-nitrophenyl butyrate and 4-nitrophenyl- $\beta$ - $D$ glucoside) according to protocols described by Manzanares et al. (1998); Rodríguez-Gómez et al. (2012), Phan et al. (2013), and Bonatsou et al. (2015). The concentration of liberated $p$-nitrophenol was estimated from the absorbance obtained at $420 \mathrm{~nm}$ in a spectrophotometer (Cary1E UV-vis, Varian INC., Palo Alto, CA, United States) using the corresponding blank for each case. Results were expressed as the amount of enzyme liberating $1 \mathrm{nmol}$ of $p$-nitrophenol per hour and milliliter $\left(\mathrm{nmol} \cdot \mathrm{h}^{-1} \cdot \mathrm{mL}^{-1}\right)$ under the assay conditions for the cellular fraction.

\section{Assessment of the Probiotic Potential}

All probiotic assays described below were executed in triplicate. In all cases, results were compared with the well-known species Lactobacillus casei var. Shirota and Lactobacillus rhamnosus GG used as the control. The resistance of the LAB strains to simulated sequential in vitro gastric $(2.5 \mathrm{~h})$ and pancreatic $(3 \mathrm{~h})$ digestions were studied following the protocol described by BautistaGallego et al. (2013) at $37^{\circ} \mathrm{C}$ in an orbital shaker (150 rpm) to simulate the peristaltic movements.

The ability of predominant LAB genotypes to reduce cholesterol in the medium was evaluated following the protocol described by Kourelis et al. (2010), but with slight modifications. Cholesterol concentrations in the medium were measured using a commercial kit (BioSystems, Barcelona, Spain). Briefly, $1 \mathrm{ml}$ on an overnight $\mathrm{LAB}$ culture was centrifuged at $9,000 \times g$ for $10 \mathrm{~min}$ 
and washed twice with $0.9 \%$ of a saline buffer. The pellet was then re-suspended in the same buffer and incubated during $2 \mathrm{~h}$ at room temperature (starvation phase). After that, $20 \mu \mathrm{l}$ of the suspension was inoculated in $230 \mu \mathrm{l}$ of MRS broth supplemented with $3 \mathrm{~g} / \mathrm{L}$ of Oxgall (Fluka Analytical, St. Louis, MO, United States) and $0.225 \mathrm{~g} / \mathrm{L}$ of cholesterol, and was incubated at $37^{\circ} \mathrm{C}$ in an orbital shaker at $200 \mathrm{rpm}$ for $48 \mathrm{~h}$. Then, the samples were centrifuged again, and the pellet was discarded. Finally, cholesterol was measured according to manufacturer instructions at $500 \mathrm{~nm}$ using a UV spectrophotometer (Agilent Technologies, Santa Clara, CA, United States). MRS broth + Oxgall without cholesterol were used for every sample as a control. A standard curve representing absorbance versus diverse cholesterol concentrations was obtained.

Quantitative bile salt hydrolase activity from the LAB strains was first detected following the protocol of Zago et al. (2011) with slight modifications. Briefly, overnight cultures of the bacteria were spotted on MRS agar plates containing $0.37 \mathrm{~g} / \mathrm{L} \mathrm{CaCl}_{2}$ and $0.5 \%$ of the sodium salt of glycodeoxycholic acid (GDCA) (Sigma-Aldrich). Plates were incubated at $37^{\circ} \mathrm{C}$ for $72 \mathrm{~h}$. Then, the presence of $b s h 1$ and $b s h 2$ genes was tested after DNA extraction. Bsh1 gen was amplified using the primers LpBsh1F/R (5'-GGATTACTAGACATGTGTACTGCC-3' $/ 5^{\prime}$-GCCAGCCAT TGGAACTTACTCTG-3') (Lambert et al., 2008). Bsh2 gen was amplified using the primers Bsh2F/R (5'-ATGTGTACCAGCCT AACTTATACCAATAGCCACGG-3'/5'-TTAGCGTGCCGTGGG TAGTGTCGCGACATCTGCGG-3') which were designed according to the genes sequences available in NCBI GenBank for L. pentosus strains described by Calero-Delgado et al. (2018). PCR amplifications were carried out using for $b \operatorname{sh} 1$ gene an initial denaturation step at $94^{\circ} \mathrm{C}$ for $4 \mathrm{~min}$, followed by 35 cycles each consisting of a denaturation step at $95^{\circ} \mathrm{C}$ for $15 \mathrm{~s}$, an annealing step at $48^{\circ} \mathrm{C}$ for $30 \mathrm{~s}$, and an extension step at $72^{\circ} \mathrm{C}$ for $45 \mathrm{~s}$, with a final extension step at $72^{\circ} \mathrm{C}$ for $6 \mathrm{~min}$. In the case of $b s h 2$ gene, the PCR conditions were initial denaturation step at $95^{\circ} \mathrm{C}$ for $4 \mathrm{~min}$, followed by 35 cycles each consisting of a denaturation step at $95^{\circ} \mathrm{C}$ for $15 \mathrm{~s}$, an annealing step at $69^{\circ} \mathrm{C}$ for $30 \mathrm{~s}$, and extension step at $72^{\circ} \mathrm{C}$ for $35 \mathrm{~s}$, with a final extension step at $72^{\circ} \mathrm{C}$ for $6 \mathrm{~min}$.

Hemolytic test for predominant LAB genotypes was carried out following the protocol described by Da Silva Ferrari et al. (2016). Briefly, an aliquot of an overnight culture of each LAB genotype was plated onto the Agar base (Oxoid) supplemented with $5 \%$ of defibrinated whole horse blood (Sigma) using the loop exhaustion technique. After incubation at $37^{\circ} \mathrm{C}$ for $24 \mathrm{~h}$, the hemolytic activity of the strains was determined by observing a clear zone around the colony, which indicated a complete inhibition of the medium ( $\beta$-hemolysis), a green zone or darkening of the medium, which indicated a partial hemolysis ( $\alpha$-hemolysis) or no inhibition zone ( $\gamma$-hemolysis). Enterococcus faecium LGM 16170 from the BCCM/LMG Bacteria collection was used as positive control.

The pathogen inhibition capacity of the LAB strains was evaluated using the agar well diffusion test described by BautistaGallego et al. (2013) with slight modifications. A lawn of BHI or Nutritive soft agar $(10 \mathrm{~g} / \mathrm{L})$ medium containing $10^{5} \mathrm{CFU} / \mathrm{mL}$ of Listeria monocytogenes NTC10357 or Escherichia coli NTC43894 were poured onto Petri dishes. After solidification, a hole was made in the center of the plate. $100 \mu \mathrm{l}$ of a $48 \mathrm{~h}$ of cellfree MRS broth of the different LAB strains was inoculated and allowed to diffuse at $4^{\circ} \mathrm{C}$ for $30 \mathrm{~min}$. To verify the nature of the possible inhibitory effect, aliquots of untreated supernatant, treated with $10-25 \mathrm{mg} / \mathrm{ml}$ proteinase $\mathrm{K}$ (Sigma) and supernatant neutralized with $0.1 \mathrm{M} \mathrm{KOH}$ were analyzed. Plates were examined for halos around the hole after incubation at $37^{\circ} \mathrm{C}$ for $24 \mathrm{~h}$.

The antibiotic susceptibility of the LAB isolates was assessed through the disk diffusion method. Briefly, $100 \mu \mathrm{l}$ of 8 $\log _{10} \mathrm{CFU} / \mathrm{mL} \mathrm{LAB}$ culture was inoculated in $4 \mathrm{ml}$ of MRS $0.75 \%$ agar and spread in plates. Once dried, antibiotics disk (Liofilchem, Italy) were applied to the surface of the plates, including erythromycin $(15 \mu \mathrm{g})$, tetracycline $(30 \mu \mathrm{g})$, gentamicin $(10 \mu \mathrm{g})$, penicillin $(10 \mu \mathrm{g})$, nalidixic acid $(30 \mu \mathrm{g})$, ampicillin $(10 \mu \mathrm{g})$, streptomycin $(10 \mu \mathrm{g})$, vancomycin $(30 \mu \mathrm{g})$, chloramphenicol (30 $\mu \mathrm{g})$, clindamycin (2 $\mu \mathrm{g})$, kanamycin (30 $\mu \mathrm{g})$, and cefotaxime $(30 \mu \mathrm{g})$. Inhibition-zone diameters were measured after $24 \mathrm{~h}$ incubation at $37^{\circ} \mathrm{C}$ and compared with known standard given by the Clinical and Laboratory Standard Institute (CLSI) for antimicrobial susceptibility testing (Clinical and Laboratory Standards Institute, 2012) as described by Charteris et al. (2000). Results were expressed in terms of resistance $(\mathrm{R})$, intermediate (I) and susceptible (S) according to the diameter halo obtained.

The ability to produce enzymes of probiotic interests by the predominant LAB genotypes was also studied, specifically their capacity to produce the $\alpha$-glucosidase, $\beta$-galactosidase, and phytase enzymes. The activities were evaluated by measuring the amount of $p$-nitrophenol liberated from different chromogenic substrates (4-nitrophenyl- $\alpha$-D-glucoside, 4-nitrophenyl- $\beta$-Dgalactosidase), while phytase activity was evaluated by measuring the release of inorganic phosphorus from sodium phytate (Haros et al., 2005; Bonatsou et al., 2015). The concentration of liberated p-nitrophenol was estimated from the absorbance obtained at $420 \mathrm{~nm}$ in a spectrophotometer (CarylE UV-vis) using a suitable blank for each case, while inorganic phosphorus was measured at $405 \mathrm{~nm}$. One unit of enzymatic activity was defined as the amount of enzyme liberating $1 \mathrm{nmol}$ of inorganic phosphorous or $p$-nitrophenol per hour and milliliter $\left(\mathrm{nmol} \cdot \mathrm{h}^{-1} \cdot \mathrm{mL}^{-1}\right)$ under the assay conditions for the cellular fraction.

\section{Statistical Analysis}

Significant differences among LAB strains for the different technological and probiotic tests assayed were determined by an analysis of variance using the one-way ANOVA module of Statistica 7.1 software (Statsoft Inc., Tulsa, OK, United States) and the Scheffé post hoc comparison test. A multivariate analysis was also performed for detecting overall similarity between predominant genotypes and characteristics (technological and probiotic features). The study comprised a cluster analysis based on the Euclidean distance, using the Ward method, and a bicluster which grouped simultaneously according to characteristics and genotypes. For multivariate analysis, the plugin XLSTAT (v. 2017) and the MultiBiplot package (Vicente Villardón, 2016) were used. 


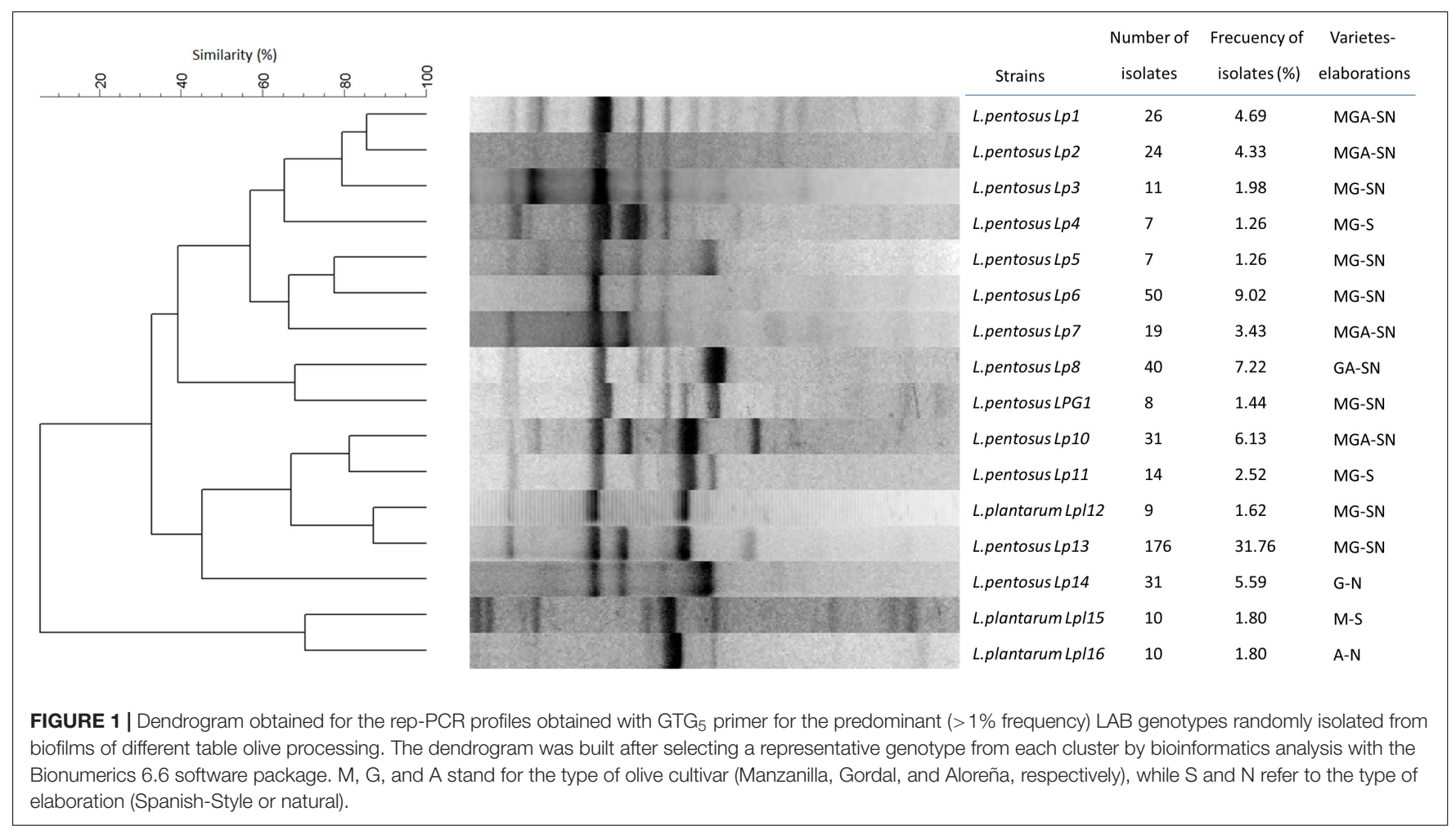

\section{RESULTS}

\section{LAB Biodiversity in Olive Biofilms}

In this work, a total of $554 \mathrm{LAB}$ isolates were obtained exclusively from olive biofilms of different industries, cultivars and processing methods. LAB isolates were first genotyped by rep-PCR analysis with GTG $_{5}$ primer. After clustering analysis, a total of 79 different genotypes were obtained for a cut-off value of $85 \%$, but only 16 genotypes had a frequency higher $>1 \%$, which accounted for the $85.39 \%$ of the total population $(n=473)$. Figure 1 shows the dendrogram built exclusively for these 16 predominant genotypes, using a representative isolate selected by the bioinformatics software for each genotype. The dominant genotype was Lp13 (31.77\%), with this strain being a ubiquitous genotype found in practically all types of elaborations (except in Aloreña green natural olives), followed by genotype Lp6 (9.03\%). The rest of the predominant genotypes had an isolation frequency ranging from 1.26 (Lp4 and Lp5) to $7.22 \%$ (Lp8). Lp1, Lp2, Lp7, and Lp10 were the most disseminated genotypes being present in all type of elaborations and varieties (Figure 1). The predominant 16 genotypes were then identified by molecular methods using sequencing of $16 \mathrm{~S}$ rDNA gene and multiplex PCR of the recA gene (data not shown). Thirteen of these genotypes were assigned to L. pentosus species (80.15\%), including Lp13 and Lp6, while the other three were identified as L. plantarum (5.24\%). Thus, the interspecific biodiversity in the sampled population was relatively low, because only one species (L. pentosus) accounted for $80.15 \%$ of the total identified isolates. Conversely, this species had the highest intra-specific diversity, with 13 of the 16 predominant genotypes. The further technological and probiotic characterisation was carried out exclusively with these 16 predominant genotypes.

Figure 2 shows the Shannon-Weiner $\left(H^{\prime}\right)$ and Simpson $(1-D) \alpha$-diversity indexes obtained for the total population (79 genotypes) as a function of processing type (Spanish-style or natural) and olive cultivar (Manzanilla, Gordal, and Aloreña) versus the type of processing. The total of isolates obtained for the Spanish-style $(n=282)$ and directly brined (natural) olives $(n=272)$ were very similar. However, the $\alpha$-diversity indexes were higher for the Spanish-style $\left(1-D=0.92, H^{\prime}=3.03\right)$ compared to the natural olives $\left(1-D=0.69, H^{\prime}=1.63\right)$. These data were also confirmed when isolates were classified according to olive cultivar and processing method. Spanish-style Manzanilla and Gordal cultivars had higher biodiversity indexes than when processed as directly brined olives (Figure 2), albeit the numbers of isolates in both cases were comparable (104 and 155 , respectively). The lowest $\alpha$-diversity indexes were obtained for Aloreña olives processed as directly brined olives, followed by Gordal and Manzanilla natural olives.

\section{Technological Tests}

Tables 1, 2 show the results obtained for the different technological tests assayed, according to the 16 selected LAB genotypes found. Modeling of the resistance and susceptibility of the strains to $\mathrm{NaCl}$ showed a good fit, with an $R^{2}$ usually above 0.97 (data not shown). The range of the NIC values (susceptibility) among LAB strains ranged from 43.5 ( $L p 3$ ) to $73.5 \mathrm{~g} / \mathrm{L}$ ( $L p 11)$, while the MIC value (resistance) ranged from 101.2 (Lp14) to $131.5 \mathrm{~g} / \mathrm{L}$ (Lpl16), with significant differences among strains according to the Scheffé post hoc comparison 


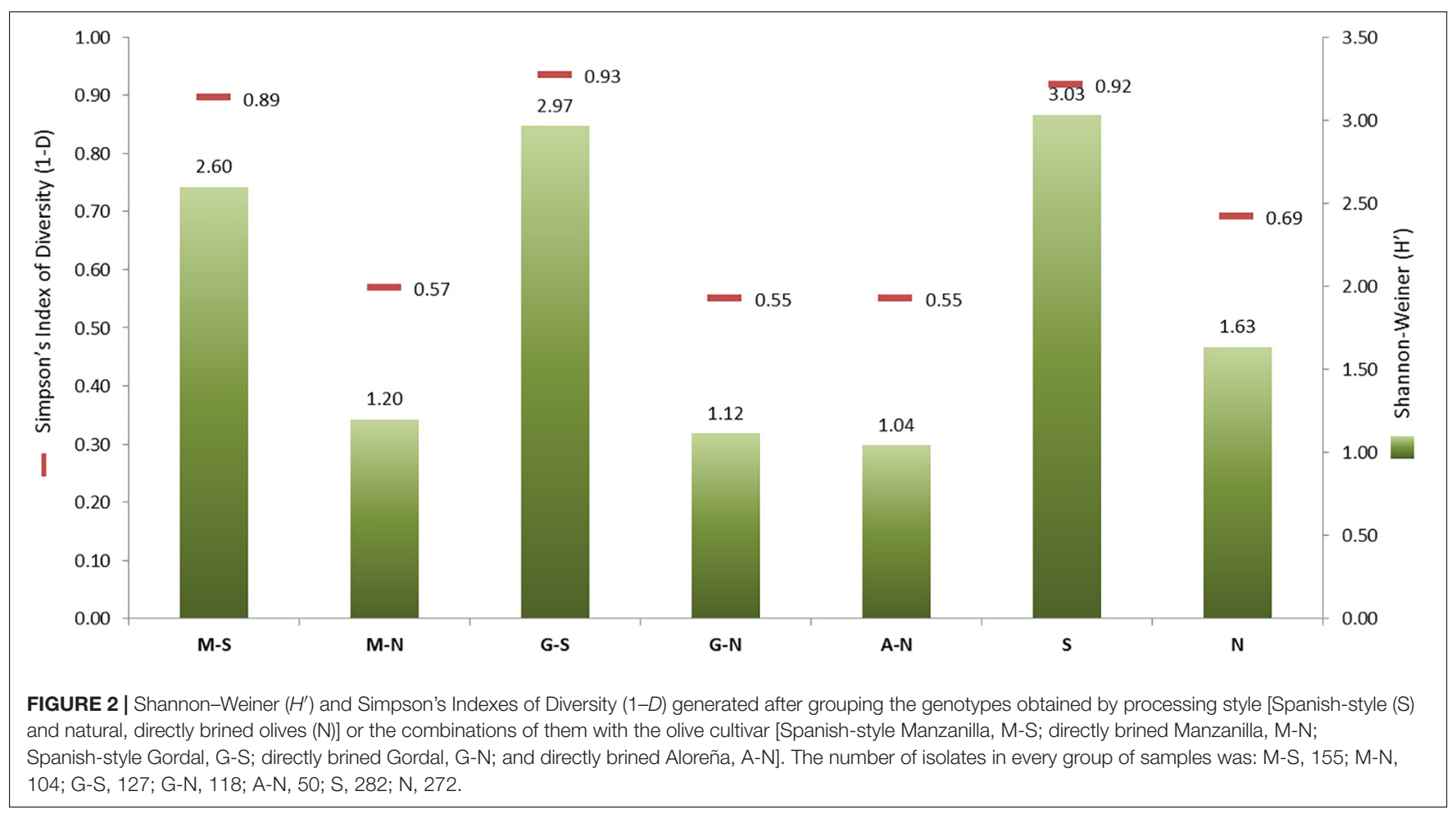

TABLE 1 | Technological characteristics in laboratory medium for the 16 predominant LAB genotypes obtained in the present study.

\begin{tabular}{|c|c|c|c|c|c|c|}
\hline \multirow[b]{2}{*}{ Strains } & \multicolumn{2}{|c|}{$\mathrm{NaCl}$ resistance } & \multicolumn{3}{|c|}{ pH cardinal values } & \multirow[b]{2}{*}{ Free acidity (\%) } \\
\hline & $\mathrm{NIC}(\mathrm{g} / \mathrm{l})$ & MIC (g/l) & $\mathrm{pH}_{\max }$ & $\mathrm{pH}_{\min }$ & $\mathrm{pH}_{\mathrm{opt}}$ & \\
\hline Lp2 & $61.19(3.61)^{a, b}$ & $105.60(0.99)^{a, b}$ & $11.24(0.05)^{\mathrm{b}, \mathrm{c}}$ & $1.49(0.06)^{\mathrm{c}, \mathrm{d}, \mathrm{e}}$ & $6.47(0.09)^{a, b, c, d}$ & $1.76(0.19)^{\mathrm{a}}$ \\
\hline Lp3 & $43.51(2.25)^{\mathrm{a}}$ & $127.00(4.38)^{c, d}$ & $11.07(0.03)^{b}$ & $1.70(0.03)^{\mathrm{e}}$ & $5.96(0.10)^{\mathrm{a}}$ & $1.66(0.09)^{\mathrm{a}}$ \\
\hline Lp4 & $61.22(3.72)^{a, b}$ & $105.76(0.14)^{a, b}$ & $11.36(0.02)^{b, c, d}$ & $1.29(0.13)^{c, d}$ & $7.03(0.10)^{\mathrm{d}, \mathrm{e}, \mathrm{f,g}}$ & $1.78(0.23)^{\mathrm{a}}$ \\
\hline Lp6 & $71.12(4.83)^{b}$ & $130.08(5.05)^{\mathrm{e}}$ & $10.24(0.03)^{a}$ & $1.51(0.07)^{\mathrm{c}, \mathrm{d}, \mathrm{e}}$ & $6.36(0.14)^{a, b, c}$ & $1.66(0.22)^{\mathrm{a}}$ \\
\hline Lp7 & $64.28(5.75)^{\mathrm{a}, \mathrm{b}}$ & $101.92(3.36)^{a, b}$ & $12.36(0.06)^{\mathrm{e}}$ & $1.39(0.07)^{\mathrm{c}, \mathrm{d}, \mathrm{e}}$ & $7.12(0.17)^{f, g, h}$ & $1.75(0.32)^{\mathrm{a}}$ \\
\hline Lp8 & $57.69(4.18)^{a, b}$ & $102.38(0.41)^{a, b}$ & $11.19(0.06)^{b}$ & $0.40(0.18)^{\mathrm{a}}$ & $7.68(0.16)^{\mathrm{h}}$ & $1.78(0.15)^{\mathrm{a}}$ \\
\hline LPG1 & $61.10(6.15)^{\mathrm{a}, \mathrm{b}}$ & $117.09(6.17)^{a, b, c, d, e}$ & $12.03(0.02)^{\mathrm{c}, \mathrm{d}, \mathrm{e}}$ & $1.38(0.07)^{\mathrm{c}, \mathrm{d}, \mathrm{e}}$ & $6.62(0.09)^{b, c, d, e, f}$ & $1.80(0.14)^{\mathrm{a}}$ \\
\hline Lp10 & $54.33(2.71)^{\mathrm{a}, \mathrm{b}}$ & $125.22(5.72)^{\mathrm{c}, \mathrm{d}, \mathrm{e}}$ & $11.27(0.03)^{\mathrm{b}, \mathrm{c}, \mathrm{d}}$ & $1.43(0.05)^{\mathrm{c}, \mathrm{d}, \mathrm{e}}$ & $7.28(0.13)^{g, h}$ & $1.79(0.08)^{\mathrm{a}}$ \\
\hline Lp11 & $73.47(2.06)^{b}$ & $99.90(3.11)^{\mathrm{a}}$ & $11.20(0.02)^{b}$ & $0.90(0.10)^{b}$ & $7.68(0.11)^{\mathrm{h}}$ & $1.76(0.09)^{\mathrm{a}}$ \\
\hline Lp/15 & $58.25(9.02)^{a, b}$ & $106.99(5.95)^{a, b}$ & $12.23(0.01)^{\mathrm{e}}$ & $1.52(0.03)^{\mathrm{d}, \mathrm{e}}$ & $6.35(0.09)^{a, b, c}$ & $1.80(0.13)^{\mathrm{a}}$ \\
\hline Lp/16 & $55.15(1.02)^{a, b}$ & $131.54(2.26)^{\mathrm{e}}$ & $12.37(0.05)^{\mathrm{e}}$ & $1.65\left(0.07^{\mathrm{d}, \mathrm{e}}\right.$ & $6.64(0.04)^{b, c, d, e, f}$ & $1.78(0.23)^{\mathrm{a}}$ \\
\hline
\end{tabular}

Values are expressed as mean and standard deviation (in parentheses) obtained from triplicate experiments. Different superscript letters, within the same column, means significant statistical difference $(p \leq 0.05)$ according to the Scheffé post hoc comparison test. NIC and MIC values for NaCl, cardinal parameters for pH, and production of titratable acidity.

test (Table 1). Thereby, the strain with the highest overall salt resistance was L. pentosus Lp6. Table 1 also shows the cardinal $\mathrm{pH}$ parameters obtained for the 16 genotypes after fitting growth curves with the Oscar model (2002), with an $R^{2}$ usually above 0.98 (data not shown). The $\mathrm{pH}_{\text {min }}$ ranged from 0.40 (strain Lp8) to $1.70(\mathrm{Lp} 3)$, the $\mathrm{pH}_{\mathrm{opt}}$ ranged from 5.96 (Lp3) to 7.96 (strains
Lp8 and $\mathrm{Lp} 11$ ), while the $\mathrm{pH}_{\max }$ ranged from 10.22 (Lp1) to 12.37 (strain Lpl16). Because the range of $\mathrm{pH}$ studied was from 2 to 12 , values extrapolated by the model outside these limits should be considered with caution. According to these data, Lp3 was one of the most acidophilus strains (because of its low $\mathrm{pH}_{\max }$ and $\mathrm{pH}_{\mathrm{opt}}$ for growth), while Lp7 was one of the most alkaline strains 
TABLE 2 | Technological characteristics for the 16 predominant LAB genotypes obtained in the present study.

\begin{tabular}{|c|c|c|c|c|}
\hline \multirow[b]{2}{*}{ Strains } & \multicolumn{3}{|c|}{ Auto and co-aggregation with yeasts $\left(O_{595} \mathrm{~nm}\right)$} & \multirow{2}{*}{$\begin{array}{c}\text { Enzymatic activity } \\
\frac{(\mathrm{U}) \mathrm{nmol}^{*} \mathrm{ml}^{-1 *} \mathrm{~h}^{-1}}{\text { Esterase }}\end{array}$} \\
\hline & Auto-aggregation & Co-aggregation Y5 & Co-aggregation Y24 & \\
\hline Lp1 & $0.78(0.34)^{a, b}$ & $1.15(0.38)^{a}$ & $2.76(0.76)^{b, c, d}$ & $43.89(9.93)^{\mathrm{a}}$ \\
\hline Lp2 & $0.51(0.10)^{\mathrm{a}}$ & $0.65(0.10)^{\mathrm{a}}$ & $0.97(0.41)^{\mathrm{a}}$ & $45.25(15.31)^{\mathrm{a}}$ \\
\hline Lp3 & $1.18(0.43)^{a, b, c}$ & $0.57(0.15)^{\mathrm{a}}$ & $1.40(0.38)^{a, b}$ & $24.01(2.75)^{\mathrm{a}}$ \\
\hline Lp4 & $3.50(0.00)^{\mathrm{e}}$ & $3.50(0.00)^{\mathrm{c}}$ & $3.50(0.00)^{d}$ & $17.92(5.28)^{\mathrm{a}}$ \\
\hline Lp5 & $3.50(0.00)^{\mathrm{e}}$ & $3.50(0.00)^{c}$ & $3.50(0.00)^{d}$ & $40.06(4.23)^{a}$ \\
\hline$L p 6$ & $0.72(0.11)^{a, b}$ & $3.50(0.00)^{c}$ & $0.68(0.06)^{\mathrm{a}}$ & $13.21(0.51)^{\mathrm{a}}$ \\
\hline$L p 7$ & $1.82(1.04)^{b, c, d}$ & $0.92(0.45)^{\mathrm{a}}$ & $0.97(0.44)^{\mathrm{a}}$ & $7.58(0.46)^{\mathrm{a}}$ \\
\hline$L p 8$ & $3.50(0.00)^{\mathrm{e}}$ & $2.57(0.36)^{b}$ & $2.76(0.34)^{b, c, d}$ & $45.54(7.26)^{a}$ \\
\hline LPG1 & $3.50(0.00)^{\mathrm{e}}$ & $3.03(0.44)^{b, c}$ & $3.46(0.08)^{d}$ & $182.69(65.60)^{b}$ \\
\hline Lp10 & $0.89(0.25)^{a, b}$ & $0.42(0.04)^{a}$ & $0.93(0.56)^{a}$ & $20.61(2.83)^{a}$ \\
\hline Lp11 & $2.18(0.83)^{\mathrm{c}, \mathrm{d}}$ & $1.09(0.41)^{\mathrm{a}}$ & $1.91(0.86)^{a, b, c}$ & $54.08(15.61)^{a}$ \\
\hline Lp/12 & $0.76(0.22)^{a, b}$ & $0.51(0.09)^{a}$ & $0.58(0.10)^{a}$ & $18.81(1.30)^{\mathrm{a}}$ \\
\hline Lp13 & $1.63(0.24)^{a, b, c}$ & $3.43(0.14)^{\mathrm{C}}$ & $3.10(0.65)^{c, d}$ & $217.23(28.84)^{b}$ \\
\hline Lp14 & $2.97(0.51)^{\mathrm{d}, \mathrm{e}}$ & $3.50(0.00)^{\mathrm{C}}$ & $3.25(0.39)^{c, d}$ & $36.78(7.24)^{a}$ \\
\hline Lp/15 & $1.48(0.28)^{a, b, c}$ & $0.93(0.25)^{\mathrm{a}}$ & $1.85(0.89)^{a, b, c}$ & $17.61(0.83)^{\mathrm{a}}$ \\
\hline Lp/16 & $0.89(0.21)^{a, b}$ & $0.57(0.10)^{\mathrm{a}}$ & $3.50(0.00)^{d}$ & $6.96(2.95)^{\mathrm{a}}$ \\
\hline
\end{tabular}

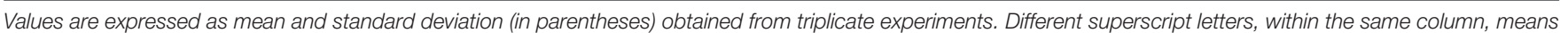

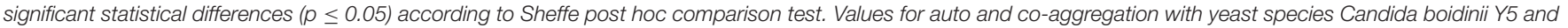
Debaryomyces etchellsii Y24 as well as esterase activity.

(high $\mathrm{pH}_{\max }$ and $\mathrm{pH}_{\mathrm{opt}}$ for growth). Not significant differences among genotypes were found for the production in laboratory medium of lactic acid, with values ranging from 1.66 (Lp3) to $1.86 \%$ (strain Lp13) (Table 1).

Genotype Lp2 showed the lowest auto-aggregation value $\left(\mathrm{OD}_{595}=0.51\right)$, while strains Lp4, Lp5, Lp8, and LPG1 had the highest $\left(\mathrm{OD}_{595}=3.50\right.$, which is the saturation limit of the spectrophotometer). Regarding co-aggregation in the presence of eukaryotes, genotypes Lp10 and Lpl12 had low values for both yeast species $\left(\mathrm{OD}_{595}<1.0\right)$, whereas strains Lp4, Lp5, LPG1, Lp13, and Lp14 showed high values $\left(\mathrm{OD}_{595}>3.0\right.$, see Table 2). Except for Lp1 (10.66 $\left.\mathrm{nmol} \cdot \mathrm{h}^{-1} \cdot \mathrm{mL}^{-1}\right)$ and Lp7 $\left(26.03 \mathrm{nmol} \cdot \mathrm{h}^{-1} \cdot \mathrm{mL}^{-1}\right)$, none of the LAB strains exhibited $\beta$-glucosidase activity but, conversely, all of them showed esterase activity, especially LPG1 $\left(182.69 \mathrm{nmol} \cdot \mathrm{h}^{-1} \cdot \mathrm{mL}^{-1}\right)$ and Lp13 $\left(217.23 \mathrm{nmol} \cdot \mathrm{h}^{-1} \cdot \mathrm{mL}^{-1}\right)$ genotypes (see Table 2 ).

\section{Probiotic Tests}

Tables 3-5 show the results of the different probiotic tests assayed according to the 16 selected LAB genotypes. Among them, the strain Lpl15 was the isolate with the highest overall survival (excluding the probiotic microorganisms used as a control) to both gastric and pancreatic digestions (37.07 and 34.59\%, respectively), while Lp10 was the most sensitive strain to the in vitro digestions $(0.00 \%$ survival). All the strains showed the ability to reduce the cholesterol in the medium but with significant statistical differences among them. The values ranged from 13.09 (Lp5) to $38.42 \%$ (Lpl15), with levels even higher than probiotic controls LcS and LrGG. The presence of bsh1 gene (but not bsh2) was detected exclusively in the $L$. plantarum strains (Lpl12, Lpl15, and Lpl16), while the bsh2 gene was found exclusively in the L. pentosus strains Lp2, Lp4, Lp7, Lp10, Lp13, and Lp14.

$\beta$-hemolysis activity was detected for all $L$. plantarum genotypes (Lpl12, Lpl15, and Lpl16), but not for any of the 13 L. pentosus genotypes studied. All genotypes assayed were able to produce the inhibition of the food-borne pathogens E. coli and L. monocytogenes but, in general, the inhibition halo was broader for E. coli (ranged from 21.0 to $24.0 \mathrm{~mm}$ ) than for L. monocytogenes (ranged from 12.00 to $16.00 \mathrm{~mm}$ ). This inhibition was not mediated by the presence of bacteriocins (data not shown). Lpl12 was the genotype with the highest inhibition halo for both pathogens (see Table 4). A total of 9 genotypes did not exhibit $\alpha$-glucosidase activity but, on the contrary, genotypes Lp1 and especially Lp11 showed high values $\left(>200.00 \mathrm{nmol} \cdot \mathrm{h}^{-1} \cdot \mathrm{mL}^{-1}\right)$. A total of 4 genotypes did not exhibit $\beta$-galactosidase activity, but genotypes Lp8 and Lp13 showed high values $\left(>100.00 \mathrm{nmol} \cdot \mathrm{h}^{-1} \cdot \mathrm{mL}^{-1}\right)$. On the contrary, phytase activity was widespread among the 16 genotypes assayed. This activity ranged from 1197.50 (Lp1) to $81,739.88 \mathrm{nmol} \cdot \mathrm{h}^{-1} \cdot \mathrm{mL}^{-1}$ (Lp13), showing the strain LPG1 also high values (see Table 4).

Table 5 shows the susceptibility of the 16 LAB selected genotypes to many of the main antibiotics used in medicine. For the antibiotic concentrations assayed, many of the strains were very sensitive to the antibiotics, except for vancomycin, kanamycin, nalidixic acid, streptomycin, and cefotaxime, which were resistant. In general, they have similar behaviors than the probiotic microorganisms LcS and LrGG used as controls. 
TABLE 3 | Probiotic characteristics for the 16 predominant LAB genotypes obtained in the present study.

\begin{tabular}{lccl}
\hline Strains & $\begin{array}{c}\text { \% Survival gastric } \\
\text { digestion }\end{array}$ & $\begin{array}{c}\text { \% Survival pancreatic } \\
\text { digestion }\end{array}$ & $\begin{array}{c}\text { \% Cholesterol } \\
\text { removal }\end{array}$ \\
\hline Lp1 & $2.60(0.78)^{\mathrm{a}, \mathrm{b}}$ & $20.29(15.38)^{\mathrm{a}, \mathrm{b}}$ & $20.82(1.90)^{\mathrm{a}, \mathrm{b}, \mathrm{c}}$ \\
Lp2 & $0.59(0.04)^{\mathrm{a}, \mathrm{b}}$ & $73.29(18.79)^{\mathrm{b}}$ & $13.44(1.90)^{\mathrm{a}}$ \\
Lp3 & $0.03(0.01)^{\mathrm{a}, \mathrm{b}}$ & $0.42(0.18)^{\mathrm{a}}$ & $14.02(4.06)^{\mathrm{a}}$ \\
Lp4 & $7.43(2.45)^{\mathrm{a}, \mathrm{b}, \mathrm{c}}$ & $6.85(2.45)^{\mathrm{a}}$ & $30.30(2.66)$ \\
Lp5 & $11.88(0.05)^{\mathrm{a}, \mathrm{b}, \mathrm{c}, \mathrm{d}}$ & $0.02(0.01)^{\mathrm{a}}$ & $13.09(1.98)^{\mathrm{a}}$ \\
Lp6 & $10.84(3.81)^{\mathrm{a}, \mathrm{b}, \mathrm{c}, \mathrm{d}}$ & $22.07(21.24)^{\mathrm{a}, \mathrm{b}}$ & $20.29(2.90)^{\mathrm{a}, \mathrm{b}, \mathrm{c}}$ \\
Lp7 & $5.41(2.87)^{\mathrm{a}, \mathrm{b}}$ & $0.91(0.81)^{\mathrm{a}}$ & $30.29(1.56)^{\mathrm{b}, \mathrm{c}, \mathrm{d}}$ \\
Lp8 & $0.00(0.00)^{\mathrm{a}, \mathrm{b}}$ & $6.82(9.64)^{\mathrm{a}}$ & $18.31(0.10)^{\mathrm{a}, \mathrm{b}}$ \\
LpG1 & $2.60(0.00)^{\mathrm{a}, \mathrm{b}}$ & $23.79(3.85)^{\mathrm{a}, \mathrm{b}}$ & $25.31(1.34)^{\mathrm{a}, \mathrm{b}, \mathrm{c}, \mathrm{d}}$ \\
Lp10 & $0.00(0.00)^{\mathrm{a}, \mathrm{b}}$ & $0.00(0.00)^{\mathrm{a}}$ & $27.43(2.38)^{\mathrm{a}, \mathrm{b}, \mathrm{c}, \mathrm{d}}$ \\
Lp11 & $5.31(2.00)^{\mathrm{a}, \mathrm{b}}$ & $0.00(0.00)^{\mathrm{a}}$ & $23.91(0.51)^{\mathrm{a}, \mathrm{b}, \mathrm{c}, \mathrm{d}}$ \\
Lp/12 & $1.47(0.74)^{\mathrm{a}, \mathrm{b}}$ & $12.23(2.48)^{\mathrm{a}}$ & $32.75(3.38)^{\mathrm{b}, \mathrm{c}, \mathrm{d}}$ \\
Lp13 & $0.23(0.01)^{\mathrm{a}, \mathrm{b}}$ & $7.43(2.79)^{\mathrm{a}}$ & $25.29(0.98)^{\mathrm{a}, \mathrm{b}, \mathrm{c}, \mathrm{d}}$ \\
Lp14 & $1.12(0.24)^{\mathrm{a}, \mathrm{b}}$ & $0.90(0.09)^{\mathrm{a}}$ & $22.74(4.49)^{\mathrm{a}, \mathrm{b}, \mathrm{c}}$ \\
Lp/15 & $37.07(2.07)^{\mathrm{d}, \mathrm{e}}$ & $34.59(2.57)^{\mathrm{a}, \mathrm{b}}$ & $38.42(2.84)^{\mathrm{d}}$ \\
Lp/16 & $35.00(5.99)^{\mathrm{c}, \mathrm{d}, \mathrm{e}}$ & $13.82(0.21)^{\mathrm{a}}$ & $35.03(2.33)^{\mathrm{c}, \mathrm{d}}$ \\
LcS & $25.34(16.31)^{\mathrm{b}, \mathrm{c}, \mathrm{d}, \mathrm{e}}$ & $35.48(19.64)^{\mathrm{a}, \mathrm{b}}$ & $32.31(1.41)^{\mathrm{b}, \mathrm{c}, \mathrm{d}}$ \\
LrGG & $56.32(10.18)^{\mathrm{e}}$ & $28.82(0.36)^{\mathrm{a}, \mathrm{b}}$ & $32.80(2.36)^{\mathrm{b}, \mathrm{c}, \mathrm{d}}$ \\
\hline
\end{tabular}

Values are expressed as mean and standard deviation (in parentheses) obtained from duplicated experiments. Different superscript letters, within the same column, means significant statistical differences $(p \leq 0.05)$ according to Sheffé post hoc comparison test. Percentage of survival to simulated gastric, pancreatic digestions, and percentage of the cholesterol removal in the medium. Data were compared with the recognized probiotic microorganisms Lactobacillus casei Shirota (LCS) and Lactobacillus rhamnosus GG (LrGG).

\section{Multivariate Analysis}

The automatic selection of clusters base on genotype entropy (Figure 3), revealed the presence of three main groups, which profiles differed mainly (most discriminatory variables) on the production of lactic acid, $\alpha$-glucosidase, the presence of bsh 1 gene, gastric and pancreatic digestion. This way, there were two groups composed of four elements; the first one (Lp6, Lpl16, LPL12, and Lpl15) included all the L. plantarum genotypes, which showed very similar behaviours among them but had a great dissimilarity with the rest of $L$. pentosus genotypes (except Lp6). The second cluster included Lp1, Lp2, Lp3, and Lp14 genotypes with low contrast among them and, apparently, with neither of them representing all the group properties. Finally, the third group included the rest of $L$. pentosus genotypes, with high similarities among some of them but finding different subclusters (LPG1 and Lp13; Lp11, Lp5, and Lp8; Lp7, Lp4, and Lp10). Therefore, the clusters could be a useful tool for a further selection of the genotypes used for new expected starter cultures.

The bicluster analysis has the advantage over the unidimensional cluster of relating each genotype with their characteristics allowing the assessment of their properties in a glance. In this analysis, the first appreciation is the clear segregation of Lp3 over the rest of genotypes because of its high susceptibility respecting the other strains to the antibiotics clindamycin, erythromycin, and streptomycin, and low values of resistance to pancreatic, gastric digestion, and cholesterol removal (Figure 4). However, the second cluster (Lp6, Lpl16, Lpl12, and Lpl15) is similar to that previously observed in

TABLE 4 | Probiotic characteristics for the 16 predominant LAB genotypes obtained in the present study.

\begin{tabular}{|c|c|c|c|c|c|}
\hline \multirow[b]{2}{*}{ Strains } & \multicolumn{2}{|c|}{ Pathogens inhibition } & \multicolumn{3}{|c|}{ Enzymatic activities (U)nmol $\mathrm{ml}^{-1 *} \mathrm{~h}^{-1}$} \\
\hline & Ec & $L m$ & $\beta$-galactosidase & Phytase & $\alpha$-glucosidase \\
\hline Lp1 & 21.00 & 12.00 & $0.00(0.00)^{\mathrm{a}}$ & $1197.50(74.35)^{\mathrm{a}}$ & $208.70(24.61)^{\mathrm{e}}$ \\
\hline Lp2 & 24.00 & 15.00 & $55.25(18.87)^{a, b, c}$ & $11946.49(3861.70)^{a, b}$ & $0.00(0.00)^{\mathrm{a}}$ \\
\hline Lp3 & 22.00 & 0.00 & $53.08(1.31)^{a, b, c}$ & $7674.71(938.30)^{a, b}$ & $126.38(4.13)^{\mathrm{c}, \mathrm{d}}$ \\
\hline Lp4 & 23.00 & 15.00 & $47.65(11.39)^{a, b, c}$ & $3638.42(971.55)^{a, b}$ & $70.68(22.15)^{\mathrm{b}, \mathrm{c}}$ \\
\hline Lp5 & 23.00 & 12.00 & $0.00(0.00)^{\mathrm{a}}$ & $18242.12(2570.98)^{a, b}$ & $0.00(0.00)^{a}$ \\
\hline Lp6 & 23.00 & 13.00 & $20.68(2.91)^{\mathrm{a}}$ & $5089.82(155.69)^{a, b}$ & $0.00(0.00)^{\mathrm{a}}$ \\
\hline Lp7 & 24.00 & 13.00 & $33.05(6.48)^{a, b}$ & $4024.19(390.16)^{a, b}$ & $50.68(6.35)^{a, b}$ \\
\hline Lp8 & 24.00 & 13.00 & $127.08(31.95)^{\mathrm{b}, \mathrm{c}}$ & $28021.32(4163.95)^{\mathrm{b}}$ & $0.00(0.00)^{\mathrm{a}}$ \\
\hline LPG1 & 24.00 & 14.00 & $314.28(95.59)^{d}$ & $54246.34(17135.20)^{\mathrm{C}}$ & $0.00(0.00)^{a}$ \\
\hline Lp10 & 24.00 & 16.00 & $53.47(1.09)^{a, b, c}$ & $8358.40(408.51)^{a, b}$ & $0.00(0.00)^{\mathrm{a}}$ \\
\hline Lp11 & 24.00 & 14.00 & $0.00(0.00) a$ & $21676.81(7883.44)^{a, b}$ & $293.93(55.08)^{f}$ \\
\hline Lp/12 & 24.00 & 16.00 & $48.47(2.88)^{a, b, c}$ & $9584.65(62.39)^{a, b}$ & $0.00(0.00)^{\mathrm{a}}$ \\
\hline Lp13 & 24.00 & 14.00 & $140.64(27.46)^{\mathrm{C}}$ & $81739.88(19270.01)^{d}$ & $0.00(0.00)^{a}$ \\
\hline Lp14 & 24.00 & 11.00 & $38.61(11.53)^{a, b}$ & $6916.17(1071.31)^{a, b}$ & $174.68(30.01)^{d, e}$ \\
\hline Lp/15 & 24.00 & 15.00 & $0.00(0.00)^{\mathrm{a}}$ & $4434.58(107.32)^{a, b}$ & $0.00(0.00)^{a}$ \\
\hline Lp/16 & 24.00 & 13.00 & $12.36(4.87)^{\mathrm{a}}$ & $1122.13(551.09)^{a}$ & $18.46(7.73)^{a, b}$ \\
\hline LCS & 22.00 & 14.00 & ND & $1197.50(74.35)^{\mathrm{a}}$ & ND \\
\hline LrGG & 22.00 & 0.00 & ND & $11946.49(3861.70)^{a, b}$ & ND \\
\hline
\end{tabular}

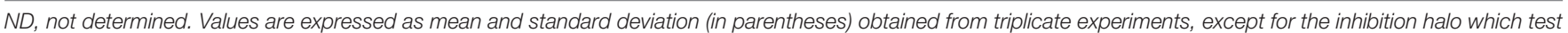

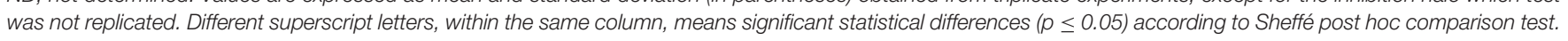

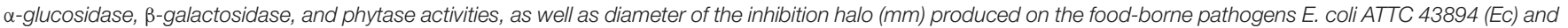

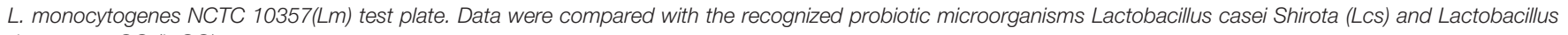
rhamnosus GG (LrGG). 
TABLE 5 | Probiotic characteristics for the 16 predominant LAB genotypes obtained in the present study.

\begin{tabular}{|c|c|c|c|c|c|c|c|c|c|c|c|c|}
\hline CEPAS/ & \multicolumn{12}{|c|}{ Diameter of inhibition zone ( $\mathrm{mm})$} \\
\hline ANTB & $\mathbf{E}$ & $\mathbf{T}$ & CN & $\mathbf{P}$ & NA & MP & $\mathbf{S}$ & VA & C & CD & $\mathbf{K}$ & FOX \\
\hline T T & $32 S$ & $21 S$ & 161 & $7 S$ & $\mathrm{OR}$ & 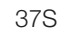 & $7 \mathrm{R}$ & $\mathrm{OR}$ & $29 S$ & $39 S$ & R & n \\
\hline Lp2 & $32 S$ & $21 S$ & 171 & $32 S$ & $\mathrm{OR}$ & & $6 \mathrm{R}$ & $\mathrm{OR}$ & $29 S$ & $39 S$ & R & $8 \mathrm{R}$ \\
\hline LPJ & $30 S$ & $20 S$ & $12 \mathrm{R}$ & $28 \mathrm{~S}$ & $\mathrm{OR}$ & 2 & $6 \mathrm{R}$ & $\mathrm{OR}$ & $S$ & 0 & 11 & R \\
\hline Lp4 & $29 S$ & 171 & $14 \mathrm{R}$ & $23 S$ & $\mathrm{OP}$ & 2 & $6 \mathrm{R}$ & $\mathrm{OR}$ & $26 S$ & $14 \mathrm{R}$ & $\mathrm{R}$ & $R$ \\
\hline Lp5 & $30 S$ & $20 S$ & $13 R$ & 101 & $\mathrm{OR}$ & 33 & $7 \mathrm{R}$ & $\mathrm{OR}$ & 30 & 7 & $\pi n$ & $6 \mathrm{R}$ \\
\hline Lp6 & $27 S$ & $17 \mid$ & $9 \mathrm{R}$ & $40 S$ & $\mathrm{OR}$ & $31 S$ & $6 \mathrm{R}$ & $\mathrm{OR}$ & $29 S$ & $7 R$ & $\mathrm{OR}$ & $23 S$ \\
\hline Lp7 & $27 S$ & $20 S$ & $12 \mathrm{R}$ & $20 S$ & $\mathrm{OR}$ & 30 & $7 \mathrm{R}$ & $\mathrm{OR}$ & $26 S$ & $12 \mathrm{R}$ & $6 \mathrm{R}$ & $6 \mathrm{R}$ \\
\hline Lp8 & $27 S$ & $20 S$ & $14 \mathrm{R}$ & $20 S$ & $\mathrm{OR}$ & 31 & $7 R$ & $\mathrm{OR}$ & $27 S$ & $8 \mathrm{R}$ & $7 R$ & $6 \mathrm{R}$ \\
\hline LPG1 & $27 S$ & 191 & 151 & $22 S$ & $\mathrm{OR}$ & $31 S$ & $6 \mathrm{R}$ & $\mathrm{OR}$ & $26 S$ & $9 R$ & $7 \mathrm{R}$ & $6 \mathrm{R}$ \\
\hline Lp10 & $26 S$ & $19 \mid$ & $13 \mathrm{R}$ & $16 \mid$ & $\mathrm{OR}$ & $30 S$ & $6 \mathrm{R}$ & $\mathrm{OR}$ & $28 \mathrm{~S}$ & $11 R$ & $6 \mathrm{R}$ & $7 R$ \\
\hline Lp11 & $29 S$ & $21 S$ & $16 \mid$ & $25 S$ & $\mathrm{OR}$ & $24 S$ & $6 \mathrm{R}$ & $\mathrm{OR}$ & $28 S$ & $8 R$ & $7 \mathrm{R}$ & $7 R$ \\
\hline Lp/12 & $30 S$ & $20 S$ & $13 R$ & $23 S$ & $\mathrm{OR}$ & $35 S$ & $\mathrm{OR}$ & $\mathrm{OR}$ & $25 S$ & $13 \mathrm{R}$ & $\mathrm{OR}$ & $8 \mathrm{R}$ \\
\hline Lp13 & $27 S$ & $18 \mid$ & 151 & $23 S$ & $\mathrm{OR}$ & $32 S$ & $6 \mathrm{R}$ & $\mathrm{OR}$ & $29 S$ & $8 \mathrm{R}$ & $6 \mathrm{R}$ & $7 R$ \\
\hline Lp14 & $31 S$ & $22 S$ & 191 & $28 S$ & $\mathrm{OR}$ & $32 S$ & $12 \mathrm{R}$ & $\mathrm{OR}$ & $29 S$ & $35 S$ & $8 R$ & $8 \mathrm{R}$ \\
\hline Lp/15 & $30 S$ & $20 S$ & $11 \mathrm{R}$ & $22 S$ & $\mathrm{OR}$ & $32 S$ & $\mathrm{OR}$ & $\mathrm{OR}$ & $28 S$ & $8 \mathrm{R}$ & $\mathrm{OR}$ & $11 \mathrm{R}$ \\
\hline Lp/16 & $30 S$ & 171 & $13 R$ & $26 S$ & $\mathrm{OR}$ & $35 S$ & $6 R$ & $\mathrm{OR}$ & $31 \mathrm{~S}$ & $8 R$ & $7 \mathrm{R}$ & 161 \\
\hline LCS & $28 S$ & $20 S$ & $11 \mathrm{R}$ & $22 S$ & OR & $35 S$ & $7 R$ & $\mathrm{OR}$ & $29 S$ & $33 S$ & OR & $8 \mathrm{R}$ \\
\hline LrGG & $27 S$ & $20 S$ & $11 \mathrm{R}$ & $21 S$ & $\mathrm{OR}$ & $37 S$ & $7 \mathrm{R}$ & $\mathrm{OR}$ & $29 S$ & $31 S$ & $\mathrm{OR}$ & $7 R$ \\
\hline
\end{tabular}

Values are expressed as diameter of the inhibition zone $(\mathrm{mm})$ for the antibiotics $E$, erythromycin $(15 \mu \mathrm{g})$; TE, tetracycline; $C N$, gentamicin $(10 \mu \mathrm{g}) ; P$, penicillin (10 $\mu \mathrm{g}) ; \mathrm{NA}$, nalidixic acid (30 $\mu \mathrm{g}) ; \mathrm{AMP}$, ampicillin $(10 \mu \mathrm{g}) ; \mathrm{S}$, streptomycin $(10 \mu \mathrm{g}) ; \mathrm{VA}$, vancomycin $(30 \mu \mathrm{g}) ; \mathrm{C}$, chloramphenicol $(30 \mu \mathrm{g}) ; \mathrm{CD}$, clindamycin $(2 \mu \mathrm{g}) ; \mathrm{K}$, kanamycin $(30 \mu \mathrm{g})$ and FOX, cefotaxime $(30 \mu \mathrm{g})$. The letters indicate: $S$, susceptible (zone diameter $\geq 20 \mathrm{~mm}$ ); I, intermediate (zone diameter, 15-19 mm); and $R$, resistant (zone diameter $\leq 14$ ), according to the standard given by Clinical and Laboratory Standards Institute (2012). Antibiotic susceptibility, determined by diffusion assay, against the high consumption antibiotics.

Figure 3 and is characterized by the higher susceptibility to the antibiotic cefotaxime and resistance to antibiotics tetracycline, streptomycin, kanamycin, and gentamycin, resistance to $\mathrm{NaCl}$, pancreatic and gastric digestion, and cholesterol removal, while show rather low values of $\alpha$-glucosidase, auto-aggregation and co-aggregation with yeasts, esterase, phytase, and $\alpha$-galactosidase activities. Also, the cluster composed of LPG1 and Lp13 is very homogeneous and presents high values for auto and co-aggregation with yeasts, esterase, phytase, and $\alpha$-galactosidase activities, isolation frequency, $\mathrm{pH}_{\max }$, lactic acid production, and inhibition of E. coli. The other big cluster is not as homogeneous as the previous ones commented. Although Lp10 and Lp7 had moderate high values in $\mathrm{pH}_{\max }$, lactic acid production, inhibition of E. coli and L. monocytogenes, $\mathrm{u}(\mathrm{pH})$, and $\mathrm{pH}_{\mathrm{opt}}$; conversely, most of the rest of genotypes included in this cluster had moderate to high values of $\alpha$-glucosidase and auto-aggregation and susceptibility to the antibiotics penicillin, chloramphenicol, clindamycin, erythromycin, streptomycin, kanamycin, and gentamicin. Hence, Figure 4 presents a picture (heat map) able to guide the selection of the genotype according to the properties one expects from the starter culture.

Regarding technological or probiotic characteristics, four clusters are observed. The first one, from left to right
(Figure 4, upper) includes the antibiotics cefotaxime, penicillin and chloramphenicol, $\mathrm{NaCl}$ (MIC), and $\mathrm{pH}_{\min }$; the second, antibiotics clindamycin, erythromycin, and tetracycline, as well as $\alpha$-glucosidase activity; the third and fourth includes successively following the 9 and 11 characteristics, respectively. Clustering some variables may indicate the simultaneous presence in specific genotypes. Looking for their relationships is outside the scope of this work, but such association opens a possible line of research expected to be explored in the future.

\section{DISCUSSION}

A step-by step procedure which comprises biofilm detachment, isolation, genotyping, identification, screening of technological and probiotic features, and use of multivariate analysis, was used in the present work for the study of the LAB biodiversity present in table olive biofilms and selection of the most promising strains for their use as starter cultures. Most of the recent works focusing on the study of the bacterial biodiversity in table olives have been carried out isolating microorganisms from olives brines, finding that $L$. pentosus and L. plantarum were the dominant species among LAB (Abriouel et al., 2012; Lucena-Padrós et al., 2014a,b; Tofalo et al., 2014; Comunian et al., 2017). However, scarce studies have been carried out to exclusively study the LAB biodiversity in the olive epidermis albeit these microorganisms would be directly transferred to human during olive consumption. The study of microorganisms associated to olive epidermis is more complex than in brines, because detachment of cells from mature biofilms may be not complete and therefore microbial counts would be underestimated. Benítez-Cabello et al. (2016) reported by independent culture methods (RT-PCR-DGGE) the presence of the L. plantarum group, Lactobacillus sanfranciscensis, and Lactobacillus parafarraginis in biofilms of Manzanilla and Gordal olives processed as Spanish-style. The same research group found that L. pentosus was the dominant species not only in the biofilms of directly brined Gordal olives (Benítez-Cabello et al., 2015) but also in the same cultivar when processed as Spanish-style (Domínguez-Manzano et al., 2012). On the contrary, Cocolin et al. (2013) reported that L. plantarum was the dominant LAB species present in the biofilms of Italian olives (Nocellare etnea cultivar) processed both as lye-treated or natural olives. The number of genotypes (biodiversity) for L. plantarum was higher in natural olives than in lye-treated olives (Cocolin et al., 2013). This results contrast with the data obtained in the present study, where the presence of LAB genotypes was higher in the Spanish-style than in natural olives. In directly brined processes, hydrolysis of phenolic compounds is achieved more slowly than in lye-treated olives (Garrido-Fernández et al., 1997). Many of these degraded phenolic compounds are powerful antibacterial compounds which hinder the growth of LAB species during olive fermentation (Medina et al., 2010). Therefore, the growth of LAB species (at least for L. pentosus) in not lye-treated olives may be limited to only the LAB genotypes with higher resistance to phenolic compounds, characteristic that reduces their biodiversity. The behavior would also be modulated by the 


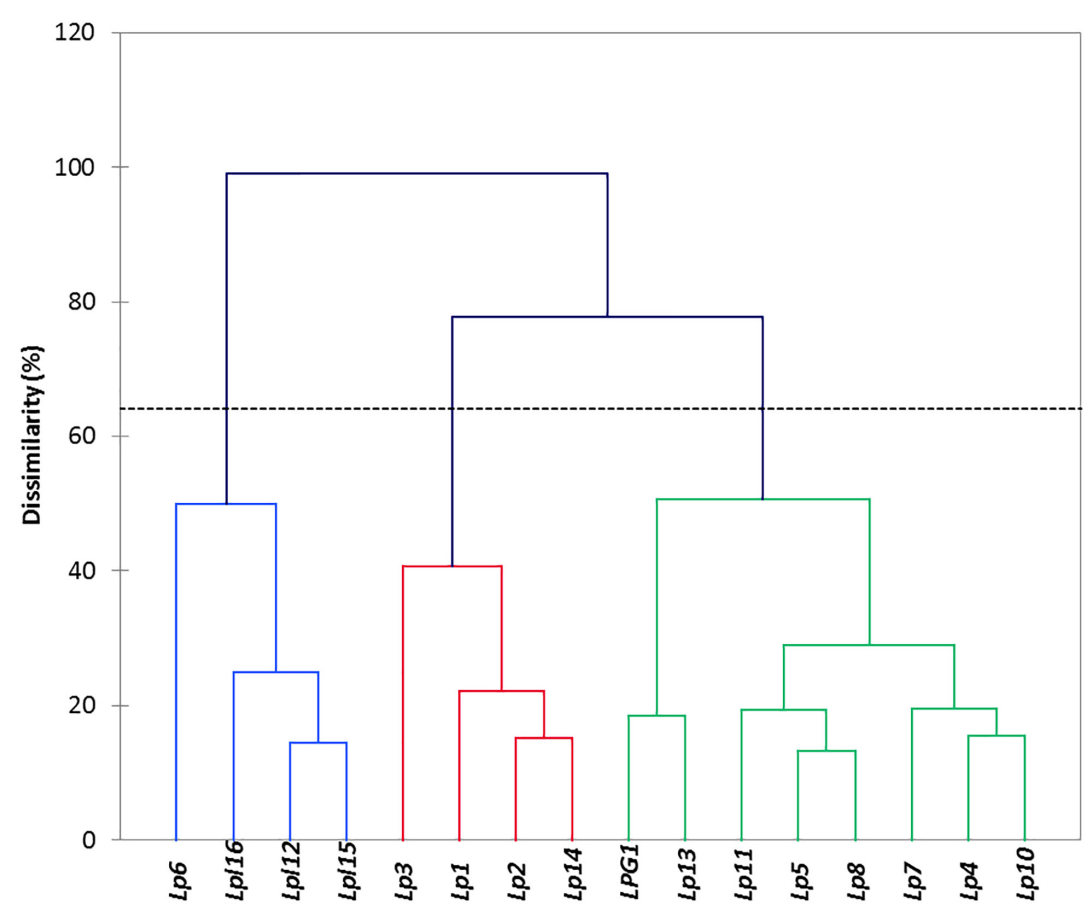

FIGURE 3 | Clustering obtained after multivariate analysis using the XLSTAT software. Cluster indicates the relation between genotypes, based on the results of the probiotics and technological tests.

concentrations of such compounds in olives and brines which will depend on the type of table olive style, elaboration and also differs among olive cultivars (Medina et al., 2010).

Lucena-Padrós et al. (2014a) performed an interesting study of the microbial genetic diversity in Spanish-style fermentations by RAPD-PCR. Among a total of 638 LAB isolates obtained from brines in two industries, they found 144 different genotypes, the most assigned to L. pentosus species, but few of them also belong to $L$. plantarum and $L$. paraplantarum species. This contrast with data obtained in the present study. A total of 79 genotypes were discriminated among $554 \mathrm{LAB}$ isolates obtained from biofilms of different industries, cultivars and styles. This work demonstrates that the selective environment governing table olive biofilms may induce lower genetic biodiversity than brines, due to the circumstance that not all LAB genotypes can adhere to fruit epidermis.

The 16 predominant LAB genotypes obtained from olives biofilms were then subjected to technological and probiotic tests for selection of the best multifunctional starters. Previous studies have proved the existence in table olive fermentations of LAB strains with potential probiotic characteristics, isolated from Spanish (Bautista-Gallego et al., 2013), Italian (Botta et al., 2014), Portuguese (Peres et al., 2014), or Greek (Argyri et al., 2013) olive brine fermentations. However, no study has been carried out till now specifically with strains isolated from table olive biofilms. This is a very exciting issue because the adherence is an important requirement for selection of $\mathrm{LAB}$ strains with probiotic potential since one should prove the ability of the selected strain to adhere to the olive surface, turning olives as a delivery vehicle of probiotic microorganisms to consumers (Arroyo-López et al., 2015).

Multivariate analysis was used for grouping genotypes as a function of their probiotic and technological features. This statistical approach is appropriate when researchers must manage and analyze a large amount of data of a considerable number of genotypes. In the last years, many researchers have used this methodology for the selection of the most promising starters for table olive processing, using principal component analysis or hierarchical cluster analysis to reach their goals (Bautista-Gallego et al., 2013; Bevilacqua et al., 2013; Botta et al., 2014; Porru et al., 2018). In this work, not only the genotypes were clustered based on their overall characteristics, but also the bicluster mapped the properties that each group had as well as the individual characterisation of the diverse strains. The initial 16 genotypes were reduced to only 3 great phenotypes, one that included the L. plantarum genotypes group (plus Lp6 strain) and other 2 clusters with the rest of $L$. pentosus genotypes, according with the low biodiversity observed. However, the bicluster has shown that even considering the low general variability; the selected genotypes have individual specific characteristics which may be of particular interest for special cases (e.g., L. plantarum for lowering the cholesterol levels or L. pentosus Lp13 and LpG1 for their high levels of esterase and phytase activities).

Therefore, the selection of a single strain which had the best or highest values for all characteristics is a great challenge. If one would have to choose among the selected LAB genotypes only one for its use as multifunctional starter, maybe L. pentosus Lp13 (or LPG1) would be the most attractive because, in 


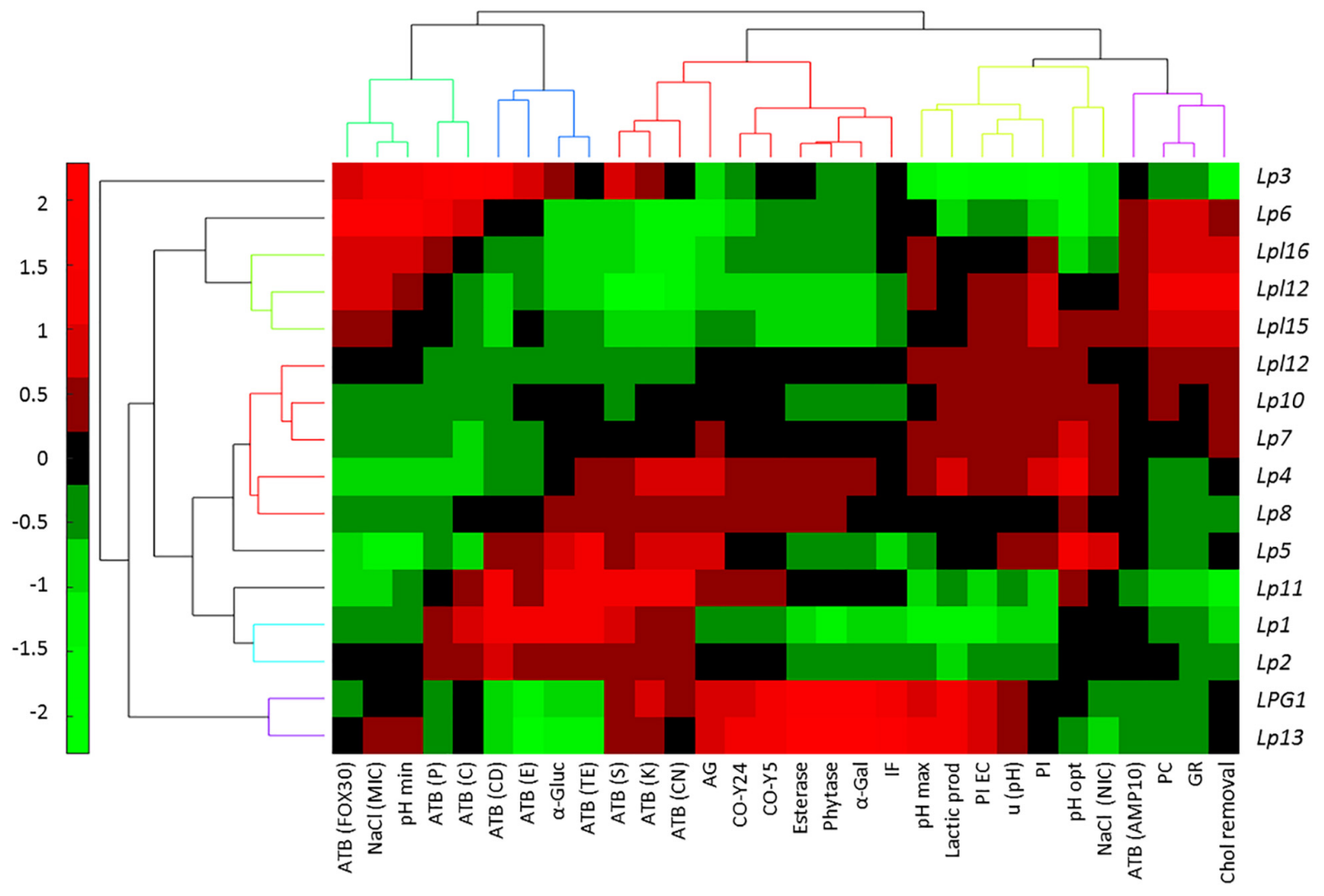

FIGURE 4 | Bicluster obtained after a multivariate analysis of genotypes, based on the probiotics and technological tests, using the Multibiplot Software. Cells' colors represent the genotype contribution to each variable. The meanings of the abbreviations are: ATB(FOX30), antibiotic cefotaxime; NACI(MIC), minimum inhibitory concentration of sodium chloride; $\mathrm{pH}$ (min), minimum $\mathrm{pH}$ value; ATB(P10), penicillin antibiotic; ATB(C30), chloramphenicol antibiotic; ATB(CD2), clindamycin antibiotic; ATB(E15), erythromycin antibiotic; $\alpha$-Gluc, $\alpha$-glucosidase; ATB(TE), tetracycline antibiotic; ATB(S10); streptomycin antibiotic; ATB(K30), kanamycin antibiotic; ATB(CN10), gentamycin antibiotic; AG, auto-aggregation; CO-Y24, co-aggregation with yeast $Y 24$; CO-Y5, co-aggregation with yeast $Y 5$; Esterase; Phytase; $\alpha$-Galact, $\alpha$-galactosidase; IF, isolation frequency; $\mathrm{pH}_{\text {max }}$, maximum growth $\mathrm{pH}$; Lactic prod, Lactic acid production; $\mathrm{PI} \mathrm{EC}$; E. coli inhibition; $\mathrm{u}(\mathrm{pH})$, maximum area obtained for $\mathrm{pH}$; PL, Listeria monocytogenes inhibition; $\mathrm{pH}_{\mathrm{opt}}$, optimum growth $\mathrm{pH}$; $\mathrm{NaCl}(\mathrm{NIC})$, non-inhibitory concentration of sodium chloride; ATB(AMP10), ampicillin antibiotic; PC, pancreatic digestion; GR, gastric digestion; Chol removal, cholesterol removal.

addition to a good performance for many of the technological and probiotic tests, was the genotype more frequently found (presumably because of its high imposition frequency during fermentation) as well as its high titratable acidity production (homofermentative metabolism), possibility of inoculation at high $\mathrm{pH}$ levels, esterase (production of aromas and degradation of bitter compounds), $\beta$-galactosidase (important in lactose assimilation), and phytase activity (necessary for assimilation of phosphate and other minerals).

\section{CONCLUSION}

Lactobacillus pentosus was the predominant species found at industrial scale in Spanish table olives biofilms, albeit certain genotypes of L. plantarum were also detected. At genotype level, biodiversity was higher in the Spanish-style table olive biofilms than in those of directly brined olives. The multivariate analysis based on technological and probiotic data showed that the main 16 genotypes obtained could be clustered in 3 great phenotypes, with some strains with potential application as multifunctional starters (especially L. pentosus Lp13 and LpG1 genotypes). Data obtained in the present study showed the selective environment that governs table olive biofilms, where not all LAB genotypes has the ability to adhere on and, as a result, the reduced biodiversity of its flora.

\section{DATA AVAILABILITY}

No datasets were generated or analyzed for this study.

\section{AUTHOR CONTRIBUTIONS}

$\mathrm{AB}-\mathrm{C}$ carried out the experimental work and helped in the writing of the manuscript. BC-D assisted in part of the experimental work. FR-G led part of the general design of the experiments and assisted in the experimental work. RJ-D contributed in the general design of the experiments and supervision. AG-F carried out the statistical analysis and also 
helped in the writing of the manuscript. FA-L supervised and contributed in the general design of the experiments and wrote the manuscript.

\section{FUNDING}

This research was funded by the Spanish Government (Project OliFilm AGL-2013-48300-R: http://olifilm.science.com. es/). AB-C thanks the Spanish Ministry of Economy and

\section{REFERENCES}

Abriouel, H., Benomar, N., Cobo, A., Caballero, N., Fernández-Fuentes, M. A., Pérez-Pulido, R., et al. (2012). Characterization of lactic acid bacteria from naturally-fermented Manzanilla Aloreña green table olives. Food Microbiol. 32, 308-316. doi: 10.1016/j.fm.2012.07.006

Abriouel, H., Benomar, N., Lucas, R., and Gálvez, A. (2011). Culture-independent study of the diversity of microbial populations in brines during fermentation of naturally-fermented Aloreña green table olives. Int. J. Food Microbiol. 144, 487-496. doi: 10.1016/j.ijfoodmicro.2010.11.006

Argyri, A. A., Zoumpopoulou, G., Karatzas, K. A., Tsakalidou, E., Nychas, G. J., Panagou, E. Z., et al. (2013). Selection of potential probiotic lactic acid bacteria from fermented olives by in vitro tests. Food Microbiol. 33, 282-291. doi: 10. 1016/j.fm.2012.10.005

Arroyo-López, F. N., Bautista-Gallego, J., Domínguez-Manzano, J., RomeroGil, V., Rodríguez-Gómez, F., García-García, P., et al. (2012). Formation of lactic acid bacteria-yeasts communities on the olive surface during spanish-style manzanilla fermentations. Food Microbiol. 32, 295-301. doi: 10.1016/j.fm.2012. 07.003

Arroyo-López, F. N., García-García, P., Rodríguez-Gómez, F., and GarridoFernández, A. (2015). "Olives: types and consumption," in The Encyclopedia of Food and Health, Vol. 4, eds B. Caballero, P. Finglas, and F. Toldrá (Oxford: Academic Press), 167-170.

Barrangou, R., Yoon, S. S., Breidt, F. Jr., Fleming, H. P., and Klaenhammer, T. R. (2002). Identification and characterization of Leuconostoc fallax strains isolated from an industrial sauerkraut fermentation. Appl. Environ. Microbiol. 68, 2877-2884. doi: 10.1128/AEM.68.11.5452-5458.2002

Bautista-Gallego, J., Arroyo-López, F. N., Rantsiou, K., Jiménez-Díaz, R., GarridoFernández, A., and Cocolin, L. (2013). Screening of lactic acid bacteria isolated from fermented table olives with probiotic potential. Food Res. Int. 50, 135-142. doi: 10.1016/j.foodres.2012.10.004

Benítez-Cabello, A., Bautista-Gallego, J., Garrido-Fernández, A., Rantsiou, K., Cocolin, L., Jiménez-Díaz, R., et al. (2016). RT-PCR-DGGE analysis to elucidate the dominant bacterial species of industrial Spanish-style green table olive fermentations. Front. Microbiol. 7:1291. doi: 10.3389/fmicb.2016.01291

Benítez-Cabello, A., Romero-Gil, V., Rodríguez-Gómez, F., GarridoFernández, A., Jiménez-Díaz, R., and Arroyo-López, F. N. (2015). Evaluation and identification of poly-microbial biofilms on natural green Gordal table olives. Antonie Van Leeuwenhoek 108, 597-610. doi: 10.1007/s10482-0150515-2

Bevilacqua, A., Beneduce, L., Sinigaglia, M., and Corbo, M. R. (2013). Selection of yeasts as starters cultures for table olives. J. Food Sci. 78, M742-M751. doi: 10.1111/1750-3841.12117

Blana, V., Grounta, A., Tassou, C., Nychas, G. J. E., and Panagou, E. Z. (2014). Inoculated fermentation of green olives with potential probiotic Lactobacillus pentosus and Lactobacillus plantarum starter cultures isolated from industrially fermented olives. Food Microbiol. 38, 208-218. doi: 10.1016/j.fm.2013.09.007

Bonatsou, S., Benítez, A., Rodríguez-Gómez, F., Panagou, E. Z., and Arroyo-López, F. N. (2015). Selection of yeasts with multifunctional features for application as starters in natural black table olive processing. Food Microbiol. 46, 66-73. doi: 10.1016/j.fm.2014.07.011

Botta, C., Langerholc, T., Cencič, A., and Cocolin, L. (2014). In vitro selection and characterization of new probiotic candidates from table olive microbiota. PLoS One 9:e94457. doi: 10.1371/journal.pone.0094457
Competitiveness for their FPI grant, while BC-D thanks the Andalusian Ministry of Economy, Science and Innovation by her pre-doctoral contract.

\section{ACKNOWLEDGMENTS}

We acknowledge support of the publication fee by the CSIC Open Access Publication Support Initiative through its Unit of Information Resources for Research (URICI).

Calero-Delgado, B., Martín-Platero, A. M., Pérez-Pulido, A. J., Benítez-Cabello, A., Casimiro-Soriguer, C. S., Martínez-Bueno, M., et al. (2018). Draft genome sequences of six Lactobacillus pentosus strains isolated from brines of traditionally fermented spanish-style green table olives. Genome Announc. 6:e00379-e18. doi: 10.1128/genomeA.00379-18

Charteris, W. P., Kelly, P. M., Morelli, L., and Collins, J. K. (2000). Effect of conjugated bile salts on antibiotic susceptibility of bile salt-tolerant Lactobacillus and Bifidobacterium isolates. J. Food Prot. 63, 1369-1376. doi: 10.4315/0362-028X-63.10.1369

Chranioti, C., Kotzekidou, P., and Gerasopoulos, P. (2018). Effect of starter cultures on fermentation of naturally and alkali-treated cv. Conservolea green olives. LWT Food Sci. Technol. 89, 403-408. doi: 10.1016/j.lwt.2017.11.007

Clinical and Laboratory Standards Institute (2012). Performance Standards for Antimicrobial Susceptibility Testing: Twenty-Second Informational Supplement. CLSI Document M100-S22. Wayne, PA: Clinical Laboratory Standard Institute.

Cocolin, L., Alessandria, V., Botta, C., Gorra, R., De Filippis, F., Ercolini, D., et al. (2013). NaOH-debittering induces changes in bacterial ecology during table olives fermentation. PLoS One 8:e69074. doi: 10.1371/journal.pone.0069074

Comunian, R., Ferrocino, I., Paba, A., Daga, E., Campus, M., Di Salvo, R., et al. (2017). Evolution of microbiota during spontaneous and inoculated Tonda di Cagliari table olives fermentation and impact on sensory characteristics. $L W T$ Food Sci. Technol. 84, 64-72. doi: 10.1016/j.lwt.2017.05.039

Da Silva Ferrari, I., de Souza, J. V., Ramos, C. L., da Costa, M. M., Schwan, R. F., and Dias, F. S. (2016). Selection of autochthonous lactic acid bacteria from goat dairies and their addition to evaluating the inhibition of Salmonella typhi in artisanal cheese. Food Microbiol. 60, 29-38. doi: 10.1016/j.fm.2016.06.014

De Bellis, P., Valerio, F., Sisto, A., Lonigro, S., and Lavermicocca, P. (2010). Probiotic table olives: microbial populations adhering on olive surface in fermentation sets inoculated with the probiotic strain Lactobacillus paracasei IMPC2.1 in an industrial plant. Int. J. Food Microbiol. 140, 6-13. doi: 10.1016/j. ijfoodmicro.2010.02.024

Domínguez-Manzano, J., Olmo-Ruiz, C., Bautista-Gallego, J., Arroyo-López, F. N., Garrido-Fernández, A., and Jiménez-Díaz, R. (2012). Biofilm formation on abiotic and biotic surfaces during Spanish style green table olive fermentation. Int. J. Food Microbiol. 157, 230-238. doi: 10.1016/j.ijfoodmicro.2012. 05.011

Garrido-Fernández, A., Fernández-Díez, M. J., and Adams, R. M. (1997). Table Olives Production and Processing. London: Chapman \& Hall. doi: 10.1007/9781-4899-4683-6

Gevers, D., Huys, G., and Swings, J. (2001). Applicability of rep-PCR fingerprinting for identification of Lactobacillus species. FEMS Microbiol. Lett. 205, 31-36. doi: 10.1111/j.1574-6968.2001.tb10921.x

Haros, M., Bielecka, M., and Sanz, Y. (2005). Phytase activity as a novel metabolic feature in Bifidobacterium. FEMS Microbiol. Lett. 247, 231-239. doi: 10.1016/j. femsle.2005.05.008

Heperkan, D. (2013). Microbiota of table olive fermentation and criteria of selection for their use as starters. Front. Microbiol. 4:143. doi: 10.3389/fmicb. 2013.00143

Hurtado, A., Requant, C., Bordons, A., and Rozes, N. (2012). Lactic acid bacteria from fermented olives. Food Microbiol. 31, 1-8. doi: 10.1016/j.fm.2012.01.006

IOC (2019). World Table Olive Figures. Madrid: IOC.

Kourelis, A., Kotzamanidis, C., Litopoulou-Tzanetaki, E., Scouras, Z. G., Tzanetakis, N., and Yiangou, M. (2010). Preliminary probiotic selection of dairy and human yeast strains. J. Biol. Res. 13:93. 
Lambert, J. M., Bongers, R. S., de Vos, W. M., and Kleerebezem, M. (2008). Functional analysis of four bile salt hydrolase and penicillin acylase family members in Lactobacillus plantarum WCFS1. Appl. Environ. Microbiol. 74, 4719-4726. doi: 10.1128/AEM.00137-08

Lanza, B. (2013). Abnormal fermentation in table-olive processing: microbial origin and sensory evaluation. Front. Microbiol. 4:91. doi: 10.3389/fmicb.2013. 00091

León-Romero, A., Domínguez-Manzano, J., Garrido-Fernández, A., ArroyoLópez, F. N., and Jiménez-Díaz, R. (2006). Formation of in vitro mixed-species biofilms by Lactobacillus pentosus and yeasts isolated from spanish-style green table olive fermentations. Appl. Environ. Microbiol. 82, 689-695. doi: 10.1128/ AEM.02727-15

Lucena-Padrós, H., Caballero-Guerrero, B., Maldonado-Barragán, A., and Ruiz Barba, J. L. (2014a). Genetic diversity and dynamics of bacterial and yeast strains associated with Spanish-style Green table olive fermentations in large manufacturing companies. Int. J. Food Microbiol. 190, 72-78. doi: 10.1016/j. ijfoodmicro.2014.07.035

Lucena-Padrós, H., Caballero-Guerrero, B., Maldonado-Barragán, A., and Ruiz Barba, J. L. (2014b). Microbial diversity and dynamics of Spanish-style green table-olive fermentations in large manufacturing companies through culturedependent Techniques. Food Microbiol. 42, 154-165. doi: 10.1016/j.fm.2014. 03.020

Magurran, A. E. (2004). "Measuring biological diversity blackwell science," in Biological Diversity: Frontiers in Measurement and Assessment, eds B. J. McGill and A. Magurran (Oxford: Oxford University Press), 105.

Manzanares, P., de Graaff, L. H., and Visser, J. (1998). Characterization of galactosidases from Aspergillus niger: purification of a novel $\alpha$-galactosidase activity. Enzyme Microb. Tech. 22, 383-390. doi: 10.1016/S0141-0229(97) 00207-X

Martorana, A., Alfonzo, A., Gaglio, R., Settanni, L., Corona, O., La Croce, F., et al. (2017). Evaluation of different conditions to enhance the performances of Lactobacillus pentosus OM13 during industrial production of Spanishstyle table olives. Food Microbiol. 61, 150-158. doi: 10.1016/j.fm.2016. 08.007

Medina, E., Gori, C., Servili, M., de Castro, A., Romero, C., and Brenes, M. (2010). Main variables affecting the lactic acid fermentation of table olives. Int. J. Food Sci. Technol. 45, 1291-1296. doi: 10.1111/j.1365-2621.2010.02274.x

Oscar, T. P. (2002). Development and validation of a tertiary simulation model for predicting the potential growth of Salmonella typhimurium on cooked chicken. Int. J. Food Microbiol. 76, 177-190. doi: 10.1016/S0168-1605(02)00025-9

Peres, C. M., Alves, M., Hernandez-Mendoza, A., Moreira, L., Silva, S., Bronze, M. R., et al. (2014). Novel isolates of lactobacilli from fermented portuguese olive as potential probiotics. LWT Food Sci. Technol. 59, 234-246. doi: 10.1016/ j.lwt.2014.03.003

Phan, M. A. T., Wang, J., Tang, J., Lee, Y. Z., and Ng, K. (2013). Evaluation of $\alpha$-glucosidase inhibition potential of some flavonoids from Epimedium brevicornum. LWT Food Sci. Technol. 53, 492-498. doi: 10.1016/j.lwt.2013. 04.002

Pino, A., De Angelis, M., Todaro, A., Van Hoorde, K., Randazzo, C., and Caggia, C. (2018). Fermentation of nocellara etnea table olives by functional starter cultures at different low salt concentrations. Front. Microbiol. 9:1125. doi: 10. 3389/fmicb.2018.01125

Porru, C., Rodríguez-Gómez, F., Benítez-Cabello, A., Jiménez-Díaz, R., Zara, G., Budroni, M., et al. (2018). Genotyping, identification and multifunctional features of yeasts associated to Bosana naturally black table olive fermentations. Food Microbiol. 69, 33-42. doi: 10.1016/j.fm.2017.07.010

Rodríguez-Gómez, F., Romero-Gil, V., Arroyo-López, F. N., Roldán-Reyes, J., Torres-Gallardo, R., Bautista-Gallego, J., et al. (2017). Assessing the challenges in the application of potential probiotic lactic acid bacteria in the large-scale fermentation of spanish-style table olives. Front. Microbiol. 8:915. doi: 10.3389/ fmicb.2017.00915

Rodríguez-Gómez, F., Romero-Gil, V., Bautista-Gallego, J., Garrido-Fernández, A., and Arroyo-López, F. N. (2012). Multivariate analysis to discriminate yeast strains with technological applications in table olive processing. World J. Microbiol. Biotechnol. 28, 1761-1770. doi: 10.1007/s11274-011-0990-1

Ruiz-Barba, J. L., and Jiménez-Díaz, R. (2012). A novel Lactobacillus pentosuspaired starter culture for Spanish-style green olive fermentation. Food Microbiol. 30, 253-259. doi: 10.1016/j.fm.2011.11.004

Ruiz-Barba, J. L., Maldonado-Barragán, A., and Jiménez Díaz, R. (2005). Smallscale total DNA extraction from bacteria and yeast for PCR applications. Anal. Biochem. 347, 333-335. doi: 10.1016/j.ab.2005.09.028

Tofalo, R., Perpetuini, G., Schirone, M., Ciarrocchi, A., Fasoli, G., Suzzi, G., et al. (2014). Lactobacillus pentosus dominates spontaneous fermentation of Italian table olives. LWT Food Sci. Technol. 57, 710-717. doi: 10.1016/j.lwt.2014.01.035

Toledo-Arana, A., Valle, J., Solano, C., Arrizubieta, M. J., Cucarella, C., Lamata, M., et al. (2001). The enterococcal surface protein, Esp, is involved in Enterococcus faecalis biofilm formation. Appl. Environ. Microbiol. 67, 4538-4545. doi: 10. 1128/AEM.67.10.4538-4545.2001

Torriani, S., Felis, G. E., and Dellaglio, F. (2001). Differentiation of Lactobacillus plantarum, L. pentosus, and L. paraplantarum by recA gene sequence analysis and multiplex PCR assay with recA gene-derived primers. Appl. Environ. Microbiol. 67, 3450-3454. doi: 10.1128/AEM.67.8.3450-3454.2001

Vicente Villardón, J. L. (2016). Multibiplot: A Package for Multivariate Analysis Using Biplots. Salamanca: Universidad de Salamanca.

Zago, M., Fornasari, M. E., Carminati, D., Burns, P., Suàrez, V., Vinderola, G., et al. (2011). Characterization and probiotic potential of Lactobacillus plantarum strains isolated from cheeses. Food Microbiol. 28, 1033-1040. doi: 10.1016/j.fm. 2011.02.009

Conflict of Interest Statement: The authors declare that the research was conducted in the absence of any commercial or financial relationships that could be construed as a potential conflict of interest.

Copyright (c) 2019 Benítez-Cabello, Calero-Delgado, Rodríguez-Gómez, GarridoFernández, Jiménez-Díaz and Arroyo-López. This is an open-access article distributed under the terms of the Creative Commons Attribution License (CC BY). The use, distribution or reproduction in other forums is permitted, provided the original author(s) and the copyright owner(s) are credited and that the original publication in this journal is cited, in accordance with accepted academic practice. No use, distribution or reproduction is permitted which does not comply with these terms. 